\title{
Thermal breakage of window glass in room fires conditions - Analysis of some
}

\section{important parameters.}

\author{
Siaka Dembele*, Ricardo A.F. Rosario, Jennifer X. Wen \\ School of Mechanical Engineering, Kingston University, London SW15 3DW, UK. \\ * Corresponding author: Tel.: +44 208417 8720, \\ Fax: +44 208417 7992, Email: s.dembele@kingston.ac.uk
}

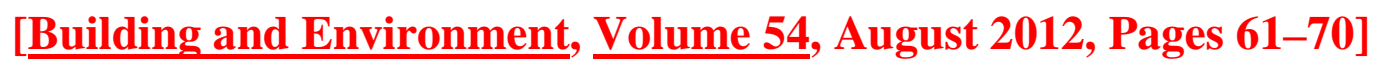

\begin{abstract}
In a compartment fire, the breakage and possible fallout of a window glass has a significant impact on the fire dynamics. The thermal breakage of glass depends on various parameters such as glass type, edge shading, edges conditions and constraints on the glass. The purpose of the present study is to investigate some of the key parameters affecting the thermal breakage of window glass in fire conditions using a recently developed and validated computer tool. Fallout is not within the scope of this study. Different boundary conditions of the glass pane (unconstrained and constrained) subjected to fire radiant heat are investigated. The analysis shows that to prevent glass thermal breakage, it is important to provide enough spacing between the frame and glass pane to accommodate the thermal expansion, and constraints on the glass structure should be avoided. The zones where the glass is likely to crack first are shown. The study also quantifies the effects of glass edge conditions on its thermal breakage in fire conditions; such analysis has not been reported in the literature due to its complexity and the statistical nature of edge flaws. The results show that an ordinary float glass mostly used in
\end{abstract}


windows, with the "as-cut" edge condition would break later and is stronger than a ground edge or polished edge glass for the scenarios investigated. The study demonstrates how a predictive tool could be employed for a better understanding of thermal breakage of window glass in fires and for design guidance.

\section{Keywords}

Glass breakage - Thermal fracture - Glass - Fire.

\section{Nomenclature}

A $\quad$ area $\left(\mathrm{m}^{2}\right)$

$\Sigma \mathrm{A} \quad$ stress-area integral

c specific heat of glass $(\mathrm{J} / \mathrm{kg} \mathrm{K})$

E Young's Modulus $\left(\mathrm{N} / \mathrm{m}^{2}\right)$

$\mathrm{F}_{\mathrm{p}} \quad$ failure probability

$\mathrm{H} \quad$ glass pane half height $(\mathrm{m})$

$\mathrm{I}_{\lambda} \quad$ spectral radiation intensity $\left(\mathrm{W} / \mathrm{m}^{2} / \mathrm{sr} / \mu \mathrm{m}\right)$

$\mathrm{I}_{\mathrm{b} \lambda} \quad$ blackbody spectral radiation intensity $\left(\mathrm{W} / \mathrm{m}^{2} / \mathrm{sr} / \mu \mathrm{m}\right)$

$\mathrm{K}_{\lambda} \quad$ glass spectral absorption coefficient $(1 / \mathrm{m})$

$\mathrm{k} \quad$ glass thermal conductivity $(\mathrm{W} / \mathrm{mK})$

L thickness of the glass pane (m)

m discrete direction in SDOM or Weibull modulus

$\mathrm{N}_{\mathrm{d}} \quad$ number of discrete directions in Spectral Discrete Ordinates Method (SDOM)

Q global displacement vector

q element nodal displacement vector or heat flux $\left(\mathrm{W} / \mathrm{m}^{2}\right)$

$\nabla \mathrm{q}_{\mathrm{rad}}$ total radiative source term $\left(\mathrm{W} / \mathrm{m}^{3}\right)$ 
$\mathrm{S}_{\mathrm{N}} \quad$ discrete ordinates method of order $\mathrm{N}$

$\mathrm{s} \quad$ width of glass shaded edge $(\mathrm{m})$

$\mathrm{T} \quad$ temperature $(\mathrm{K})$

t time (s)

${ }^{\mathrm{m}} \quad$ weight of discrete direction $\mathrm{m}$ in SDOM

$\mathrm{x}, \mathrm{y}, \mathrm{z}$ cartesian coordinates $(\mathrm{m})$

\section{Greek symbols}

$\alpha \quad$ absorptivity of glass or coefficient of linear expansion $(1 / \mathrm{K})$

$\beta \quad$ coefficient of thermal expansion (1/K)

$\gamma \quad$ shear strain

$\Delta \quad$ difference

$\varepsilon \quad$ emissivity of glass or strain

$\theta \quad$ polar angle between direction of radiation intensity and normal to surface (rad)

$\lambda \quad$ wavelength of radiation $(\mu \mathrm{m})$

$\mu, \xi, \eta$ direction cosines in SDOM

$\rho \quad$ reflectivity or density $\left(\mathrm{kg} / \mathrm{m}^{3}\right)$

$\sigma \quad$ stress $\left(\mathrm{N} / \mathrm{m}^{2}\right)$

$\sigma_{\max }$ maximum tensile stress $\left(\mathrm{N} / \mathrm{m}^{2}\right)$

$\sigma_{\text {nom }}$ nominal stress $\left(\mathrm{N} / \mathrm{m}^{2)}\right.$

$\bar{\sigma}_{\mathrm{u}} \quad$ unit of area strength $\left(\mathrm{N} / \mathrm{m}^{2}\right)$

$\sigma_{1,2,3}$ principal stresses $\left(\mathrm{N} / \mathrm{m}^{2}\right)$

$\tau$ transmissivity of glass or shear stress $\left(\mathrm{N} / \mathrm{m}^{2}\right)$ 
$\hat{\Omega} \quad$ radiation angular direction

\section{Subscripts}

g relative to the glass

$\mathrm{m} \quad$ discrete direction in SDOM

$\lambda \quad$ spectral

\section{Abbreviations}

Glaz3D

Kingston University 3D Cartesian Glazing thermal breakage code

SDOM

Spectral Discrete Ordinates Method (radiation model)

\section{Introduction}

The understanding of glass fracture or breakage mechanism is important in many disciplines including building design, fire safety engineering, glass manufacturing and forensic science. For the latter application, McJunkins and Thornton [1] have presented a good review of how examination of glass fracture patterns are used to aid criminal investigation in bulletscaused fractures of annealed window glass.

Another cause of window glass fracture in buildings is thermally induced stress, resulting from the uneven heating of glass by exposure to solar radiation, fire or intense radiant heat. Thermal fracture by solar radiation has been well studied and reported in the literature for single pane and double glazed windows [2, 3]. For clarity in the terminology, in the present article, fracture, breakage or cracking refer to the occurrence of single or multiple cracks in the glass, with the glass still fully in place in the frame and no new vent opened. Fallout refers to postfracture situations where a new vent is created as a result of glass pieces or the whole glass pane falling out of the frame. 
Exposure of a window glass to fire or intense radiant heat in building compartments could also cause the uneven heating of window glass and subsequent thermal breakage. Thermal fracture of glass in fire conditions before fallout is the scope of the present study. There is clearly some similarity between glass breakage in solar and fire conditions. However in fires, the physics of the problem is more complex due to the dynamics of the fire that needs to be modelled and coupled with the glass behaviour. Also in fires, the level of heat fluxes that directly affects breakage, is significantly higher than in solar problems where radiation is typically less than 1.4 $\mathrm{kW} / \mathrm{m}^{2}$. In fire safety, the need for more research on window glass breakage in fires was first highlighted by Emmons [4]. The only study then on the topic reported in [4] was the experimental work carried out at Harvard by subjecting window glass to intense radiant heat [5]. Pagni [6] followed up by making an analogy between glass fracture in fires and ice cracking: " $a$ window glass breaks in fire for the same reason that an ice cube cracks when placed in liquid. Thermal expansion places the cooler portion in tension. The exposed window heats and expands placing its cooler shaded edge in tension until it cracks at a small defect". An overview of theoretical and experimental studies on glass thermal breakage is presented in the literature [7-9].

To study thermal fracture of window glass in compartments (e.g. rooms, enclosure) fires, two main physical processes which are related to each other should be considered. The first is the heat transferred by radiation and convection from the fire source and the hot combustion products to the glass; radiation remaining the dominant mode of heat transfer in a fire environment. The second process is the mechanical stress distribution and glass fracture. Most theoretical studies on glass fracture in fire applications were concerned with improving heat transfer models, i.e. the first physical process above mentioned. It is worth noting that the glass fracture's criterion employed in all these studies for framed glass in fire environment is based on 
Pagni's criterion [6] which states that glass fracture occurs when the temperature increase in an exposed portion of the glass is sufficient to induce a pre-determined fracture (failure) stress in the shaded framed edge. An accurate modeling of heat transfer is therefore important for a good prediction of the temperature field using the energy equation, and the subsequent calculation of thermal stresses and initial fracture time. Cuzzillo and Pagni [10] carried out a good review of existing heat transfer models for glazing in fire environment. Keski-Rahkonen [11] presented a heat transfer model with linearized radiation boundary conditions to calculate the temperature and thermal stress fields. The author also established a deterministic criterion for fracture's stress in the form $\sigma \sim \Delta \mathrm{T}$ where $\Delta \mathrm{T}$ is the temperature difference between the hotter exposed area and the colder edge of the glass. A theoretical value of $\Delta \mathrm{T}=80^{\circ} \mathrm{C}$ is reported for initial fracture and cracks [11]. Further theoretical studies were presented by Pagni and Joshi for a more accurate calculation of heat transferred and temperature field in the glass and the time of first crack occurrence $[12,13]$. To handle the non-linear radiation boundary conditions which contain terms with temperature to the power 4, a Laplace transform method is proposed to obtain the transient temperature field [12,13]. Sincaglia and Barnett [14] developed a glass fracture model with emphasis on radiation wavelength dependence which was implemented in the zone type computer code Branzfire by Parry et al. [15]. Dembele et al. [16] developed an advanced radiation heat transfer model, based on a Spectral Discrete Ordinates Method (SDOM) which addressed some limitations of literature models. The model is spectral since glass is a spectrally selective material that absorbs, reflects and transmits radiation within specific wavelengths. It accounts for the diffuse nature of the radiation incident on the glass pane and provides a better handling of boundary conditions such as exterior fires radiation due to its formulation. Validation results of the one-dimensional radiation model (referred to as 1D-SDOM) have been 
presented in terms of temperature distribution in the glass and the time to first crack's occurence based on Pagni's deterministic criterion [16]. To simulate the dynamic interaction between the fire and the glazing system in a compartment, the spectral radiation model was coupled with the Computational Fluid Dynamics (CFD) code Fire Dynamics Simulator (FDS 5.0) developed at the National Institute of Standards and Technology (NIST) [17]. Successful validation and application results of the coupled tool, referred to as FDS-1D-SDOM, were presented in [18].

For thermal breakage in fire conditions, few studies have however investigated thermal stresses i.e. the second physical process above mentioned. This is understandable if Pagni's deterministic criterion is to be employed to calculate the fracture time since the temperature (determined from heat transfer calculations) is the most important parameter. However this widely used criterion has two major limitations. Firstly it was developed for a uniform exposure of the glass pane to fire, which is not the case for many real compartment fire scenarios where the glass may be subjected to heat flux from a hot upper layer and cooler lower layer (nonuniform heating) [19]. Secondly the Pagni's deterministic criterion does not account for some real physical parameters of the glass such as edge conditions resulting from the glass manufacturing or when it is cut to size or further processed. These parameters which are of statistical or probabilistic nature have a strong influence on the glass fracture and are difficult to account for without investigating the thermal stress field. Moreover, the location of the first cracks in the glass pane could only be predicted from a detailed stress analysis. Keski-Rahkonen [11] was the first to carry out some analysis on thermal stress fields in a long strip window under fire conditions, using the $2 \mathrm{D}$ thin plate approximation (no stresses in the direction of glass thickness) and assuming no temperature gradient across the thickness of the glass. It is reported that stresses build up in the coldest parts of the panes [11]. Chow and Gao [20] did some 
thorough thermal stress analysis to understand the effect of non-uniform temperature distribution on the glass surface in fire conditions. The authors used the experimental non-uniform temperature data from [19] to derive vertical temperature profiles, which were then employed to calculate the stresses on the glass pane for different boundary conditions. Tofilo and Delichatsios [21] carried out some 2D analytical and numerical thermal stress analysis to quantify the significance of the bridling from axial elongation and the flexing stresses in calculating the maximum thermal stresses in compartment fires. The study shows some limitations of the simple glass breakage criterion in [11] and highlights the need for more thorough stress calculations. More recently Dembele et al. [22] coupled a three-dimensional thermal stress and a failure probability model with the 3D-SDOM model developed by the same authors. The failure probability model is an alternative to Pagni's deterministic criterion. Some preliminary validation results of the combined tool, referred to as "Glaz3D" were presented in [22] for some simple scenarios by comparing (i) the temperature and stresses predicted to ANSYS [23] and (ii) the time of first crack occurrence to some experimental data available in the literature. The verifications and validations studies show that the temperatures and time of first crack's occurrence predicted with Glaz3D are in relatively good agreement with most comparative experimental data [22]. These results are not repeated in the present study and the aim is not to validate Glaz3D but to employ it as a tool to explore further the stress, strain distributions and other parameters such as edge conditions and glass boundary conditions, for design guidance. Unlike most studies presented in the literature based on the 2D thin plate approximation, Glaz3D predicts the 3D thermal stress-strains distributions. For a dynamic simulation of the fire and glass behaviour, Glaz3D was coupled with FDS and the resulting tool referred to as Glaz3D-FDS [22]. 
Many parameters such as edge shading affect the thermal breakage of glass in fires. In addition to shading, the way the glass is constrained (boundary conditions) has a strong influence which is explored in the current study. Edge condition is another key parameter that strongly influences glass thermal breakage in fires. Although it is well established that glass fracture initiates at an edge defect [6], there is hardly any study in the literature to analyze and quantify the effect of the edge conditions on glass thermal breakage in fire conditions. This knowledge gap on edge conditions effects was underlined by Hassani et al. [7]. The most common way of describing the distribution of flaws, which are of statistical nature, is the Weibull probability model [24] which was implemented in Glaz3D. An analysis is carried out in the present study to quantify the effect of different glass edge conditions (as cut, grounded, polished) on the failure of window glass in typical fire conditions.

The overall objective of the present study is to investigate in more detail some important parameters such as edge conditions and boundary conditions which affect the breakage of window glass in typical compartment fires conditions and to provide some design guidance. The recently developed tool Glaz3D is employed for the analysis. The quantification of the effects of edge conditions on glass thermal breakage in room fires, has never been reported in the literature to the best of the authors' knowledge. The study also demonstrates how a predictive tool could assist in a better understanding of window glass breakage and for safety design in buildings.

\section{Theoretical analysis}

The reader may refer to reference [22] for a detailed description of the modelling approach adopted in Glaz3D. Only the main equations are recalled here. Glaz3D is structured around the following 3D sub-models: a spectral discrete ordinates radiation model (3D-SDOM), 
conduction heat transfer, thermal stress model and a Weibull probability of failure model for glass fracture.

\subsection{Spectral discrete ordinates radiation model (SDOM)}

A typical window glass assembly in a room fire scenario is shown in Fig. 1 [12]. The glass edges are framed and the remaining surface areas are either directly exposed to heat from the fire sources and combustion products or exposed to ambient. It is assumed that the speed of temperature waves is much lower than that of stress waves [11]. Therefore the transient temperature field, $\mathrm{T}(\mathrm{x}, \mathrm{y}, \mathrm{z}, \mathrm{t})$, in the glass is first calculated, then the thermal stress and the failure probability are solved. For a 3D Cartesian geometry, the temperature is determined from the energy equation:

$\rho c \frac{\partial \mathrm{T}(\mathrm{x}, \mathrm{y}, \mathrm{z}, \mathrm{t})}{\partial \mathrm{t}}=\mathrm{k}\left(\frac{\partial^{2} \mathrm{~T}(\mathrm{x}, \mathrm{y}, \mathrm{z}, \mathrm{t})}{\partial \mathrm{x}^{2}}+\frac{\partial^{2} \mathrm{~T}(\mathrm{x}, \mathrm{y}, \mathrm{z}, \mathrm{t})}{\partial \mathrm{y}^{2}}+\frac{\partial^{2} \mathrm{~T}(\mathrm{x}, \mathrm{y}, \mathrm{z}, \mathrm{t})}{\partial \mathrm{z}^{2}}\right)-\nabla \mathrm{q}_{\mathrm{rad}}(\mathrm{x}, \mathrm{y}, \mathrm{z})$

The first terms in bracket on the right-hand side (RHS) of Eq. (1) represent the conductive heat flux in the glass determined from Fourier's Law. The second term, $\nabla \mathrm{q}_{\mathrm{rad}}$, the total radiative source term or divergence of the net radiative heat flux vector, characterizes the net total radiative energy emitted or absorbed by the glass per unit time and per unit volume over all wavelengths. $\nabla \mathrm{q}_{\text {rad }}$ could be positive or negative depending on whether the glass is a net emitter or absorber (see Eq.(4) below). For an accurate calculation of temperatures and thermal stresses, $\nabla \mathrm{q}_{\mathrm{rad}}$ should be evaluated accurately. This source term is calculated in the present study from the spectral discrete ordinates method (SDOM) described below. A major advantage of the SDOM is that it is spectral i.e. wavelength dependent (glass is a spectrally selective material) and account for the diffuse nature of thermal radiation from the fire and hot combustion gases (i.e. radiation from all directions is considered). 
The 3D Spectral Radiative Transfer Equation (SRTE) in an absorbing and emitting, non scattering medium such as glass is:

$\mu \frac{\partial \mathrm{I}_{\lambda}(\mathrm{x}, \mathrm{y}, \mathrm{z}, \mathrm{t}, \hat{\Omega})}{\partial \mathrm{x}}+\xi \frac{\partial \mathrm{I}_{\lambda}(\mathrm{x}, \mathrm{y}, \mathrm{z}, \mathrm{t}, \hat{\Omega})}{\partial \mathrm{y}}+\eta \frac{\partial \mathrm{I}_{\lambda}(\mathrm{x}, \mathrm{y}, \mathrm{z}, \mathrm{t}, \hat{\Omega})}{\partial \mathrm{z}}=\mathrm{K}_{\lambda}\left[\mathrm{I}_{\mathrm{b} \lambda}(\mathrm{x}, \mathrm{y}, \mathrm{z}, \mathrm{t})-\mathrm{I}_{\lambda}(\mathrm{x}, \mathrm{y}, \mathrm{z}, \mathrm{t}, \hat{\Omega})\right]$

The fundamental quantity in the SRTE, which needs to be resolved is the spectral radiation intensity, $\mathrm{I}_{\lambda}$, which is function of the spatial location $(\mathrm{x}, \mathrm{y}, \mathrm{z})$ and the angular direction $\hat{\Omega}(\mu, \xi, \lambda)$. It is defined as the amount of radiative energy $\mathrm{dE}_{\lambda}$ streaming through a unit area perpendicular to the direction of propagation $\hat{\Omega}(\mu, \xi, \lambda)$, per unit solid angle, per unit wavelength, per unit time:

$$
\mathrm{I}_{\lambda}(\mathrm{x}, \mathrm{y}, \mathrm{z}, \mathrm{t}, \hat{\Omega})=\left[\frac{\mathrm{dE}_{\lambda}}{\mathrm{dA} \cos \theta \mathrm{d} \hat{\Omega} \mathrm{dtd} \lambda}\right]_{\mathrm{limdA}, \mathrm{d} \hat{\Omega}, \mathrm{dt}, \mathrm{d} \lambda \rightarrow 0}
$$

Once the spectral intensity field, $\mathrm{I}_{\lambda}$, is resolved, the total radiative source term is calculated as:

$$
\nabla \mathrm{q}_{\mathrm{rad}}=4 \pi \int_{\mathrm{all} \lambda} \mathrm{K}_{\lambda} \mathrm{I}_{\mathrm{b} \lambda} \mathrm{d} \lambda-\int_{\text {all } \lambda} \mathrm{K}_{\lambda}\left|\int_{\hat{\Omega}=4 \pi} \mathrm{I}_{\lambda} \mathrm{d} \hat{\Omega}\right| \mathrm{I}_{\mathrm{b} \lambda} \mathrm{d} \lambda
$$

Eq. (4) shows that an integration is needed over all solid angles $d \hat{\Omega}$ over the entire spherical space ( $4 \pi$ steradians). This is achieved in Glaz3D with the Discrete Ordinates Method [25]. The technique is based on the separation of the angular dependence $(\hat{\Omega})$ from the spatial dependence $(\mathrm{x}, \mathrm{y}, \mathrm{z})$ of the intensity in the SRTE by selecting a set of discrete directions spanning in the angular range of $4 \pi$ (quadrature scheme) with appropriate weights. The angular directions are chosen such that the products of the angular directions and their weights satisfy certain full-range and half-range moment constraints. For each discrete direction, $\hat{\Omega}_{\mathrm{m}}$, Eq. (2) becomes:

$$
\mu_{\mathrm{m}} \frac{\partial \mathrm{I}_{\mathrm{m} \lambda}(\mathrm{x}, \mathrm{y}, \mathrm{z}, \mathrm{t})}{\partial \mathrm{x}}+\xi_{\mathrm{m}} \frac{\partial \mathrm{I}_{\mathrm{m} \lambda}(\mathrm{x}, \mathrm{y}, \mathrm{z}, \mathrm{t})}{\partial \mathrm{y}}+\eta_{\mathrm{m}} \frac{\partial \mathrm{I}_{\mathrm{m} \lambda}(\mathrm{x}, \mathrm{y}, \mathrm{z}, \mathrm{t})}{\partial \mathrm{z}}=\mathrm{K}_{\lambda}\left[\mathrm{I}_{\mathrm{b} \lambda}(\mathrm{x}, \mathrm{y}, \mathrm{z}, \mathrm{t})-\mathrm{I}_{\mathrm{m} \lambda}(\mathrm{x}, \mathrm{y}, \mathrm{z}, \mathrm{t})\right]
$$


Eq. (5) is integrated over each control volume, with appropriate boundary conditions, to determine the local intensity field $I_{m \lambda}$. Each discrete direction $\hat{\Omega}_{\mathrm{m}}$ is fixed by its direction cosines $\left(\mu_{\mathrm{m}}, \xi_{\mathrm{m}}, \lambda_{\mathrm{m}}\right)$ and weights $\mathrm{w}_{\mathrm{m}}$. For an $\mathrm{S}_{\mathrm{N}}$ scheme (angular segmentation), the total number of discrete ordinates in $4 \pi$ steradian spherical space is $\mathrm{N}_{d}=\mathrm{N} \times(\mathrm{N}+2)$. The sets of directions and weights are completely invariant after any rotation of $90^{\circ}$ and satisfy the zeroth, first and second moments:

$$
\sum_{\mathrm{m}=1}^{\mathrm{N}_{\mathrm{d}}} \mathrm{w}_{\mathrm{m}}=4 \pi \quad \sum_{\mathrm{m}=1}^{\mathrm{N}_{\mathrm{d}}} \mathrm{w}_{\mathrm{m}} \mu_{\mathrm{m}}=0 \quad \sum_{\mathrm{m}=1}^{\mathrm{N}_{\mathrm{d}}} \mathrm{w}_{\mathrm{m}} \mu_{\mathrm{m}}^{2}=\frac{4 \pi}{3}
$$

Table 1 presents the directions cosines and quadrature weights of the $\mathrm{S}_{6}$ quadrature scheme for 1/8 th of a spherical space adopted for the present analysis [25]. These data are used in Eq. (5). There are $8 \times 6=48$ discrete ordinates in the total solid angle of $4 \pi$. The $S_{6}$ scheme provides intensity solutions that do not vary significantly when higher orders (e.g. $\mathrm{S}_{8}$ ) are used at the expense or higher computing times. The maximum relative differences between temperatures predicted by $S_{6}$ and $S_{8}$ are within $1 \%$ whereas the latter requires 64 discretes ordinates i.e. 1.33 times the number of directions used for $S_{6}$. It therefore offers a good compromise between accuracy and computing effort. The glass spectral absorption coefficients used in the study are given in Fig. 2 [26]. Once the radiation intensity field is calculated, the total radiative source term, $\nabla \mathrm{q}_{\text {rad }}$, used in Eq. (1) is calculated as:

$$
\nabla \mathrm{q}_{\mathrm{rad}}=\sum_{\text {all } \lambda} \mathrm{K}_{\lambda}\left[4 \pi \mathrm{I}_{\mathrm{b} \lambda}-\sum_{\mathrm{m}=1}^{\mathrm{N}_{\mathrm{d}}} \mathrm{w}_{\mathrm{m}} \mu_{\mathrm{m}}\left|\xi_{\mathrm{m}}\right| \mathrm{I}_{\mathrm{m} \lambda}\right]
$$

The spectral range $0.1 \mu \mathrm{m}$ to $100 \mu \mathrm{m}$ is used in the integration for total quantities in the present study.

\subsection{Thermal stress and probability of failure}


The thermal stress model adopted in Glaz3D is based on the potential energy and the Galerkin finite element approaches [27]. It has been adapted and validated for thermal loads relevant to glass by the present authors [22]. The potential energy and Galerkin approaches yield the set of equations:

$\mathrm{KQ}=\mathrm{F}$

where $\mathrm{Q}$ is the global displacement vector, $\mathrm{K}$ the stiffness matrix and $\mathrm{F}$ a global matrix.

The calculation of the stress and strain values can be performed once Eq. (8) is solved and the results of the global displacement, Q, and element nodal displacements, q, are obtained.

The elements normal and shear strains, $\varepsilon=\left[\varepsilon_{\mathrm{x}}, \varepsilon_{\mathrm{y}}, \varepsilon_{\mathrm{z}}, \gamma_{\mathrm{yz}}, \gamma_{\mathrm{xz}}, \gamma_{\mathrm{xy}}\right]^{\mathrm{T}}$, and normal and shear stresses $\sigma=\left[\sigma_{\mathrm{x}}, \sigma_{\mathrm{y}}, \sigma_{\mathrm{z}}, \tau_{\mathrm{yz}}, \tau_{\mathrm{xz}}, \tau_{\mathrm{xy}}\right]^{\mathrm{T}}$ vectors in the glass can be obtained from:

$\varepsilon=\mathrm{Bq}$ and $\sigma=\mathrm{D} \varepsilon=\mathrm{DBq}$

where $\mathrm{D}$ is the material matrix and $\mathrm{B}$ a $(6 \times 12)$ matrix [27].

Once the temperature field in the glass is calculated from Eq. (1), if the glass temperature changes by $\Delta \mathrm{T}(\mathrm{x}, \mathrm{y}, \mathrm{z})$ with respect to the initial state, the thermal stresses can be calculated by:

$\sigma=\mathrm{D}\left(\varepsilon-\varepsilon_{0}\right)$

where $\varepsilon_{0}=[\alpha \Delta \mathrm{T}, \alpha \Delta \mathrm{T}, \alpha \Delta \mathrm{T}, 0,0,0]^{\mathrm{T}}$

After the normal and shear stresses and strains are obtained, the principal stresses $\left(\sigma_{1}, \sigma_{2}\right.$ and $\left.\sigma_{3}\right)$, principal strains could be calculated. A quantity called the equivalent stress or Von Mises stress, $\sigma_{\mathrm{VM}}$, is commonly used in solid mechanics for material failure:

$\sigma_{\mathrm{VM}}=\sqrt{\frac{1}{2}\left[\left(\sigma_{1}-\sigma_{2}\right)^{2}+\left(\sigma_{2}-\sigma_{3}\right)^{2}+\left(\sigma_{3}-\sigma_{1}\right)^{2}\right]}$ 
Pagni's widely used glass fracture deterministic criterion [6] states that glass fracture occurs when the temperature increase in an exposed portion of the glass is sufficient to induce a pre-determined fracture (failure) stress in the framed shaded edge:

$$
\Delta \mathrm{T}=\overline{\mathrm{T}}_{\mathrm{exp} \mathrm{osed}}-\mathrm{T}_{\text {framed edge }} \geq(1+\mathrm{s} / \mathrm{H}) \frac{\sigma_{\max }}{\mathrm{E} \cdot \beta}
$$

Where $\bar{T}_{\text {exposed }}$ is the averaged temperature of the exposed area, and $T_{\text {framed edge }}$ the temperature of the framed glass edge. The advantage of this criterion is its simplicity and it yields relatively good initial fracture time under some conditions. However it has limitations: (i) it was developed for a uniform exposure of the glass pane to fire heat, (ii) it does not include the effect of the edge conditions which strongly influence fracture. As an alternative to the criterion Eq. (12) and to account for the many variable parameters in glass fracture such as edge conditions, a probability of failure model based on Weibull distribution is incorporated in Glaz3D. The model calculates the probability of the glass material failure due to thermal and load stresses. The general form of the failure probability, $\mathrm{F}_{\mathrm{p}}$, of the glass is expressed as [28]:

$$
\mathrm{F}_{\mathrm{p}}=1-\exp \left[-\left(\frac{\sigma_{\text {nom }}}{\bar{\sigma}_{\mathrm{u}}}\right)^{\mathrm{m}} \Gamma\left(1+\frac{1}{\mathrm{~m}}\right) \frac{\mathrm{A}}{\mathrm{A}_{0}} \Sigma \mathrm{A}\right]
$$

where $\mathrm{m}$ is the Weibull modulus, $\bar{\sigma}_{\mathrm{u}}$ the strength of a specimen of unit area $\mathrm{A}_{0}$, and $\Sigma \mathrm{A}$ the stress-area integral.

The $\Gamma$ gamma function is calculated from Eq. (14):

$$
\Gamma\left(1+\frac{1}{\mathrm{~m}}\right)^{\mathrm{m}}=0.5685+1.0937 \mathrm{e}^{-2.08003 \mathrm{~m}}+0.35898 \mathrm{e}^{-0.53884 \mathrm{~m}}+0.09222 \mathrm{e}^{-0.08931 \mathrm{~m}}
$$

The maximum principal stress value in the glass pane is assigned to the nominal stress $\sigma_{\text {nom }}$ in Eq. (13). The stress-area integral is expressed as: 
$\Sigma \mathrm{A}=\frac{1}{\mathrm{~N}} \sum_{1}^{\mathrm{N}}\left[\left(\frac{\sigma_{1}}{\sigma_{\text {nom }}}\right)^{\mathrm{m}}+\left(\frac{\sigma_{2}}{\sigma_{\text {nom }}}\right)^{\mathrm{m}}+\left(\frac{\sigma_{3}}{\sigma_{\text {nom }}}\right)^{\mathrm{m}}\right]$

Where $\mathrm{N}$ is the number of nodes, and $\sigma_{1}, \sigma_{2}, \sigma_{3}$ are the principal stresses calculated by the thermal stress model. Eqs. (13)-(14) are used to determine the probability of failure of the glass surface and the edge elements.

The overall failure probability (OFP) of a glass surface consisting of k elements is calculated as:

$\mathrm{OFP}=\left(1-\mathrm{F}_{\mathrm{p} 1}\right)\left(1-\mathrm{F}_{\mathrm{p} 2}\right) \ldots \ldots \ldots \ldots . . .\left(1-\mathrm{F}_{\mathrm{pk}}\right)$

It is important to note that the values of the Weibull Modulus, $\mathrm{m}$, and unit of area strength, $\overline{\mathrm{\sigma}}_{\mathrm{u}}$, are different for each type of glass and edge conditions. The values employed in the present study were obtained from a compilation of fire testing experimental data by Pilkington [29] for ordinary glass and different edge conditions (as-cut, ground, and ground and polished). An analysis is carried out in the present study on the effect of edge conditions on glass thermal breakage in fire conditions. Fig. 3 shows the different types of edge conditions investigated and Table 2 presents the Weibull Modulus and unit of area strength values for ordinary glass used in the probability of failure model [29].

\section{Results and discussions}

\subsection{Effect of boundary conditions on thermal stresses and strains distribution in glass exposed to fire radiant heat}

In this section Glaz3D is employed to investigate in more detail the effect of various boundary conditions on the thermal stresses and strains for a typical ordinary window glass subjected to fire radiant heat. This analysis is important not only to further verify the code but also for a better understanding of how these various parameters affect the breakage in fire conditions. The results may also serve as verification data for other researchers undertaking 
similar studies in the future as there is hardly any such data in the literature for fire applications. Experimental data in the literature for glazing in fire conditions are mostly the time for first crack occurrence and the glass surfaces temperatures. Glaz3D was successfully validated against such data [22]. The thermal stress profiles were satisfactorily validated against ANSYS software for simulations without the radiative source term Eq. (4) which is not accounted for by ANSYS due to its complexity. One of the main advantages of Glaz3D is that it computes more accurately this radiative source term, which directly affects the temperature and the thermal stresses and strains. However there is hardly any experimental data for detailed stress and strain distributions over the whole glass pane for fire applications.

The scenario adopted in the present study to examine the three boundary conditions is inspired from some experimental studies of glass panes subjected to radiant heat fluxes characteristic of fires [30-32]. In compartment fire scenarios radiant heat transfer is the dominant mode of heat transfer. In [30] the radiant heat flux in the experiments ranged from 3 to 10 $\mathrm{kW} / \mathrm{m}^{2}$, and in [31] from 2 to $16 \mathrm{~kW} / \mathrm{m}^{2}$. For ordinary float glass breakage in fire conditions, Mowrer [31] quoted a minimum heat flux from 4 to $5 \mathrm{~kW} / \mathrm{m}^{2}$. It is worth noting that no detailed stresses or strains distribution in the whole glass was measured by these authors [30-32]. A nonshaded glass, not constrained at the edges, uniformly heated does not break because the thermal expansion is uniform [4]. In real situations however the window glass is framed and therefore the edges are shaded as in Fig. 1. The scenario considered is based on a single window ordinary float glass pane shaded at the edges, and subjected to a uniform radiant heat flux of $6.7 \mathrm{~kW} / \mathrm{m}^{2}$ on one side (exposed side). Such heat flux value was investigated in [30] and is higher than the minimum heat for breakage for ordinary glass $4-5 \mathrm{~kW} / \mathrm{m}^{2}[31,32]$. It provides a good representation of the heat flux for analysis of the glass behaviour. Ordinary soda-lime-silica 
glass is the most common type of glass used in buildings and accounts for more than $90 \%$ of all the glasses made today. Its general weight composition with minor variations is $74 \%$ silica $\left(\mathrm{SiO}_{2}\right), 16 \%$ soda $\left(\mathrm{Na}_{2} \mathrm{O}\right), 10 \%$ lime $(\mathrm{CaO})[33]$.

The ordinary glass dimensions for the analysis are: thickness L=3mm, $300 \mathrm{~mm}$ width, $300 \mathrm{~mm}$ height and $\mathrm{s}=15 \mathrm{~mm}$ (shaded edge width). The edge condition is the same (as cut) and the three boundary conditions studied, which are encountered in practice, are (a) unconstrained glass pane, (b) glass pane constrained in the four corners and (c) glass pane fully constrained at the bottom shaded edge. For all three conditions, the glass edges are shaded. For simulations with Glaz3D, the following data are used: $\mathrm{E}=73 \mathrm{GN} / \mathrm{m}^{2}, \beta=8.75 \times 10^{-6} \mathrm{~K}^{-1}, \alpha=4.6 \times 10^{-7}$ (coefficient of linear expansion) and $\mathrm{k}=0.95 \mathrm{~W} / \mathrm{mK}$. After a mesh sensitivity analysis, meshes of 2312 elements $[34(\mathrm{Y}) * 34(\mathrm{Z}) * 2(\mathrm{X})]$ are employed as they provide a good compromise between accuracy and computing effort.

Fig. 4 shows the temperature distribution on the exposed glass surface 140s after exposure to the radiant heat of $6.7 \mathrm{~kW} / \mathrm{m}^{2}$. In the figure, "Temp" denotes the temperature. The imposed radiant heat is used as a boundary condition to solve the spectral radiative transfer equation Eq. (2) and determine the radiative source term in Eq.(4). This temperature distribution is then calculated from the energy equation, Eq.(1) and applied to all three boundary conditions. The exposed side would correspond to the fire side in a real compartment fire scenario. This exposure time (140s) corresponds approximately to the time of first crack occurrence in the unconstrained glass [30]. The initial temperature of the glass is $300 \mathrm{~K}$. The temperature on the exposed area of the glass as shown in Fig. 4 at 140s, increases to about $400 \mathrm{~K}$ in the exposed unshaded area of the glass. In comparison the temperature in the shaded edges increases only by a maximum of $20{ }^{\circ} \mathrm{C}$ to $320 \mathrm{~K}$. The temperature difference between the central area and edge is 
about $80{ }^{\circ} \mathrm{C}$ and consistent with breakage temperature reported [11-13]. The non-uniform temperature gradient distributions resulting from the edge shading induce non-uniform expansion and thermal stresses in the glass. As shown in Fig. 5a-c, for the unconstrained boundary condition (a), the central part of the glass tends to deform slightly towards the side exposed to radiant heat. The figure presents qualitatively the three sequences of the glass pane deformation at the initial time of heating (Fig. 5a), intermediate time of 70s (Fig. 5b) and final time of 140s (Fig. 5c), as predicted with Glaz3D. An analysis of the temperatures of the exposed and unexposed surfaces shows a maximum difference of about $7^{\circ} \mathrm{C}$ between the two surfaces. This temperature gradient across the glass thickness (which is neglected in most studies) causes the thermal bending as shown in the simulations, Fig. 5a-c. The results confirm the effects of thermal bending on the stress distributions as underlined in some studies [20]. Although this thermal bending may not be important as glass is a brittle material, for accuracy its effect should be accounted for as in Glaz3D which is three-dimensional. It is worth noting that for a typical compartment fire, the onset of flashover would correspond to ceiling gas temperature of about $500^{\circ} \mathrm{C}(773 \mathrm{~K})$, above the $400 \mathrm{~K}$ for ordinary glass breakage mentioned for the scenario investigated here. Glass breakage would therefore likely occur well before the onset of flashover in the room.

Figs. 6a-c show the normal stress $\sigma_{\mathrm{y}}$ in $\mathrm{Y}$ direction for the three boundary conditions $\mathrm{a}, \mathrm{b}$, and c. In the figures, 'Sy' denotes the normal stresses $\sigma_{y}$. For the unconstrained glass pane, scenario a, in Fig. 6.a, the glass is in tension in all four edges (positive stresses) and in compression in the central area (negative stresses) - this is the result of the temperature gradient in the glass and the boundary conditions. The maximum normal tensile stresses $\sigma_{\mathrm{y}}\left(53.4 \mathrm{MN} / \mathrm{m}^{2}\right)$ are located at the top and bottom edges. For boundary condition b (glass constrained in four corners) the maximum 
tensile zones are located at the top and bottom edges and also in the two lateral edges. The tensile stress increases in the lateral edges due to the corners constraints, also the glass pane shows a high compression near the constrained corners, as shown in Fig.6b. The central zone is also in compression. For boundary condition c (glass pane fully constrained at the bottom shaded area), as shown in Fig. 6.c, the glass is in tension in the y direction at the top edge where the maximum tensile stresses are located. The bottom edge is in compression because as the glass pane tries to expand, it is restrained by the constrained bottom edges generating a compression. The central area is still in compression.

The normal strains $\varepsilon_{\mathrm{y}}$ for the three boundary conditions are presented in Figs. 7a-c. 'Ey' denotes the normal strains $\varepsilon_{\mathrm{y}}$. The strain profiles predicted with Glaz3D is consistent with the stress behavior described in Figs. 6a-c. Fig.7a shows that the glass pane expands in the y direction at all four edges (positive strains) for boundary condition a. However for condition b (Fig. 7b) the glass pane expansion is restrained by the constrained edges generating small areas of maximum compression where the glass shrinks (negative strains). For the boundary condition c shown in Fig.7c, the glass pane has a compression zone just above the bottom shaded area and an expansion zone on the top edge.

For the three boundary conditions, similar behaviour is obtained in the $\mathrm{Z}$ directions for the stresses and strains $\sigma_{\mathrm{z}}$ and $\varepsilon_{\mathrm{z}}$ (not presented here for manuscript length constraints). A simple calculations with Hook's Law and the input data aforementioned show that at breakage (first crack occurrence) the breakage stress is around $50 \mathrm{MN} / \mathrm{m}^{2}$ and the corresponding breakage strain $6.8 * 10^{-4}$ for the temperature profile used (Fig. 4) for the unconstrained glass. Figs.6a and 7a show similar levels of stress and strains for maximum values which are consistent with literature [12]. As in practice the window glass is framed, to obtain the unconstrained boundary condition 
a, the spacing between the frame and the glass edge should accommodate an expansion of about $0.068 \%\left(6.8 * 10^{-4}\right)$. The maximum expansion strain in Fig. $7 \mathrm{~b}\left(3.25^{*} 10^{-4}\right)$ is lower than the maximum values in Fig. $7 \mathrm{a}\left(6.4 * 10^{-4}\right)$ which is consistent with expectations for boundary condition $\mathrm{b}$. One advantage of the detailed stress analysis is the possibility to map the areas of maximum stress where initial fracture is likely to occur. Rather than presenting the three principal stresses for the three boundary conditions, it is more convenient to show the equivalent tensile stress or Von Mises stresses $\left(\sigma_{\mathrm{VM}}\right)$ which represents the equivalent tensile stress the material is subjected to by combining all three principal stresses. From its definition Eq. (11) it is a positive quantity (i.e. tensile stress) and provides a good indication of the overall stress and the locations of the maximum equivalent tensile stresses in the glass where the initial fractures could occur (although the concept is strictly applicable to ductile materials) [34, 35]. Figs. 8a-c present the equivalent stresses for the three boundary conditions. 'VM' denotes the Von-Mises stress. The most relevant information to read from the graphs are the areas of maximum equivalent stresses where the glass will initially crack. For the unconstrained glass pane (boundary condition a), as shown in Fig. 8a, the maximum tensile stress $\left(\sim 49 \mathrm{MN} / \mathrm{m}^{2}\right)$ is located at the edges. The initial cracks will occur at an edge defects at these locations. Notice that as equivalent stresses are positive quantities the stresses in the central zone (in compression) are positive. For the glass pane constrained at the corners (condition b) the maximum equivalent stresses are located on the border of the constrained area as illustrated in Fig. 8b - initial cracks will occur at any flaw in these areas. The maximum stresses in Fig.8b are much higher than the unconstrained case Fig.8a (indicating that cracking will occur earlier than in condition a). For condition c (Fig. 8c), the maximum equivalent stresses are located near the bottom shaded area and the edges. 
The analysis clearly shows that to prevent glass failure, as a design guidance, it is important to provide enough spacing between the frame and glass pane, and avoid constraints on the glass structure. Additional constraints on an edge shaded window glass will lead to higher stress levels and earlier breakage compared to an unconstrained case. The study also demonstrates how the combination of accurate radiation heat transfer modeling and stress could help identify and map out the locations of initial cracks in the glass in fire conditions for different boundary constraints. The results presented could also serve for model verifications purposes to other researchers working on thermal fracture of glass in fires.

\subsection{Influence of edge conditions on the probability of failure of a glass pane exposed to fire radiant heat}

The analysis carried out in section 3.1 shows that an unconstrained, framed window glass pane subjected to typical fire radiant heat will develop maximum tensile stresses at the edges. This is consistent with the findings in literature [6-8]. Since breakage usually occur at an edge defect, the edge condition which is of probabilistic nature, is critical to the initial cracks prediction. Although it is widely acknowledged that the quality of the edge finish do influence glass breakage, there is hardly any literature studies to quantify this effect in fire conditions. Ordinary float glass is the most common type of glass used in windows. In this section, Glaz3D is employed to investigate the overall failure probability of an ordinary window float glass pane subjected to typical fire radiant heat for three different edge conditions commonly used by glass manufacturers: (a) as-cut edge, (b) ground edge and (c) ground and polished edge (Fig. 3). For edge condition a, the glass edges are as cut by cutters with no further processing, they are sharp. For edge condition $b$ the edge has a diamond smooth unpolished finish (ground not polished). The edges are fine polished (ground and polished) for condition (c) - this condition will be 
referred to as polished edge. The latter two edge conditions therefore require further processing which will impact on edge flaws and strength.

For the study, the ordinary float glass dimensions are: thickness $\mathrm{L}=3 \mathrm{~mm}, 500 \mathrm{~mm}$ width, 500 $\mathrm{mm}$ height and $\mathrm{s}=15 \mathrm{~mm}$ (shaded edge width). It is subjected to a uniform radiant heat flux of 9.1 $\mathrm{kW} / \mathrm{m}^{2}$ on one side. A similar scenario was investigated by Harada et al. [30]. Fig. 9 presents the overall failure probability (OFP) of the glass calculated with Glaz3D using Eq.(16) for the three edge conditions. As the exposure time of the glass to radiant heat increases, the OFP also rises as a result of the temperature rise in the central zone. Fig.9 shows that to reach a given failure probability (OFP), the "as-cut" edge takes longer time than the "ground" and "polished" edges. The glass has a $100 \%$ probability of breaking (very high risk) after 98 s for the "polished edge", 112 s for the ground edge and 160s for the "as-cut" edge. Fig.9 clearly shows that the ordinary glass pane with an edge condition "polished" will break earlier than one with edge condition "ascut". An explanation to this is the extra processing carried out on the ground and polished edge glasses, which increase the risk of introducing more flaws at the edge where the glass is likely to break. An OFP of 50\% is generally accepted as a good indication of the initial crack occurrence time in the glass pane - meaning there is $50 \%$ risk of glass fracture at that particular time. In the experiments of Harada et al. [30] a similar scenario was investigated with ordinary float glass with "as-cut" edge. For a radiant heat of $9.1 \mathrm{~kW} / \mathrm{m}^{2}$, the time to initial crack was about $90 \mathrm{~s}$ [30]. Table 3 shows the probability of the first crack occurrence considering OFPs of 50\%, 75 and 100\%. The ground and polished edges were not experimentally investigated. The $50 \%$ OFP predicted with the model for the "as-cut" edge (98s) agrees relatively well with the experimental data (90s). The findings confirm what is accepted in the glass industry that clean as-cut edges are generally considered to be the strongest edge for ordinary monolithic single pane glass. The study 
shows how the model could be employed for design guidance to quantify and predict the risk of glass fracture for a particular edge condition. Such analysis including the edge would not be feasible with the deterministic approach for instance.

\section{Conclusions}

Thermal breakage of window glass in typical fire conditions were investigated for different boundary conditions. A recently developed computer tool whose models are presented is employed for the simulations. The detailed stresses and strains distribution in the glass panes, and the locations of possible cracks locations are presented for unconstrained and constrained glass panes boundary conditions. The study show that for a shaded edge glass, to minimize the risk of glass failure and increase the time to first crack occurrence, the glass should be unconstrained with enough space between the glass pane and frame. The effect of edge conditions on the probability of failure of ordinary float glass, was also studied. Three edge conditions were considered: as-cut edge, ground edge and polished edge. The analysis shows that the "as-cut" edge is stronger and fails later than the ground and polished edges for the scenarios investigated. The computer tool employed could serve for design purposes. The work and models presented can also be the basis for future development of glass fallout models, which would require a more accurate prediction of the first crack time and location taking into account the influence of edge conditions. There is a need for more experiment data for detailed stress and strains in multiple locations in the glass pane under fire conditions. Such data, although challenging to obtain, may provide validation data for models. The results presented here may in that sense also serve as comparative data for other researchers. The analysis was limited in the study to ordinary float glass which is the most common type of glass used for window glasses. However, the approach could account for the edge conditions in the probability of failure of 
other type of glass (tempered or toughened glass, laminated glass etc...) provided the Weibull modulus and unit of area are pre-determined.

\section{Acknowledgements}

The authors gratefully acknowledge the financial support of Pilkington plc for this work.

\section{References}

[1] McJunkins SP, Thornton JI. Glass fracture analysis. A review. Forensic Sci 1973; 2:1-27.

[2] Mai YW, Jacob LJS. Thermal stress fracture of solar control window panes caused by shading of incident radiation. Mater Struct 1980; 13(4):283-8.

[3] Pilette CF, Taylor DA. Thermal stresses in double-glazed windows. Canadian J Civil Eng $1988 ; 15(5): 807-14$.

[4] Emmons HW. The needed Fire Science. In: Proceedings of the First International Symposium on Fire Safety Science, IAFSS, Berkeley, California; 1986, p. 33-53.

[5] Barth PK, Sung H. Glass Fracture under intense heating. Senior Project Report, Harvard University, Cambridge; 1977.

[6] Pagni PJ. Fire physics - promises, problems and progress. In: Proceedings of the Second International Symposium on Fire Safety Science, IAFSS, Tokyo, Japan; 1989, p. 49-66.

[7] Hassani SKS, Shields TJ, Silcock GWH. Thermal fracture of window glazing: performance of glazing in fire. J Appl Fire Sci 1994-5; 4(4):249-63.

[8] Pagni PJ. Thermal glass breakage. In: Proceedings of the Seventh International Symposium on Fire Safety Science, IAFSS, Worcester, MA, USA; 2002, p. 3-22.

[9] Chow WK, Gao Y, Chow CL. A review on fire safety in buildings with glass facade. J Appl Fire Sci 2006-7; 16(3):201-23. 
[10] Cuzzillo BR, Pagni PJ. Thermal breakage of double-pane glazing by fire. J Fire Protect Eng 1998; 9(1):1-11.

[11] Keski-Rahkonen O. Breaking of window glass close to fire. Fire Mater 1988; 12(2):61-9.

[12] Pagni PJ, Joshi AA. Glass Breaking In Fires. In: Proceedings of the Third International Symposium on Fire Safety Science, IAFSS, Edinburgh, UK; 1991, p. 791-802.

[13] Joshi AA, Pagni PJ. Fire-induced thermal fields in window glass - I Theory. Fire Safety J $1994 ; 22: 25-43$

[14] Sincaglia PE, Barnett JR, Development of a glass window fracture model for zone-type computer fire codes. J Fire Protect Eng 1997; 8(3), pp. 101-18.

[15] Parry R, Wade CA, Spearpoint M. Implementing a glass fracture module in the BRANZFIRE zone model. J Fire Protect Eng 2003; 13(3):157-83.

[16] Dembele S, Rosario RAF, Wen JX. Investigation of glazing behaviour in a fire environment using a spectral discrete ordinates method for radiative heat transfer. Numer Heat Tr B-Fund 2007; 52(6):489-506.

[17] McGrattan K, Hostikka S, Floyd J, Baum HR, Rehm RG. Fire Dynamics Simulator, Version 5, Technical Reference Guide, National Institute of Standards and Technology Special Publication 1018-5, Gaithersburg, MD, 2007.

[18] Dembele S, Rosario RAF, Wen JX, Warren PD, Dale S. Simulation of glazing behavior in fires using computational fluids dynamics and spectral radiation modelling. In: Proceedings of the Ninth International Symposium on Fire Safety Science, IAFSS, Karlsruhe, Germany, 2008, p. 1029-40.

[19] Shields TJ, Silcock GWH, Flood M. Performance of a single glazing assembly exposed to a fire in the centre of an enclosure. Fire and Materials 2002; 26:51-75. 
[20] Chow WK, Gao Y. Thermal stresses on window glasses upon heating. Constr Build Mater 2008; 22:2157-64.

[21] Tofilo P, Delichatsios M. Thermally induced stresses in glazing systems. J Fire Protect Eng 2010; 20, pp. 101-16.

[22] Dembele S, Rosario RAF, Wang QS, Warren PD, Wen JX. Thermal and stress analysis of glazing in fires and glass fracture modeling with a probabilistic approach. Numer Heat $\mathrm{Tr}$ B-Fund 2010; 58(6):419-39.

[23] ANSYS, Inc., ANSYS CFX-Solver, Release 10.0, Canonsburg, 2005.

[24] Weibull W. A statistical distribution function of wide application. J Appl Mech 1951; 18, pp. 293-7.

[25] Carlson BG, Lathrop KD. Transport theory - the method of discrete-ordinates, In Greenspan H, Kelber CN, editors. Computing Methods in Reactor Physics. New York: Gordon and Breach; 1968.

[26] Gardon R. Calculation of temperature distributions in glass plates undergoing heat treatment. J Am Ceram Soc 1958; 41, pp. 200-8.

[27] Chandrupatla TR, Belegundu AD. Introduction to Finite Elements in Engineering. 3rd ed. Prentice Hall; 2002.

[28] Warren PD. Fracture of brittle materials: effects of test method and threshold stress on the Weibull modulus. J Eur Ceram Soc 2001; 21, pp. 335-42.

[29] Pilkington Plc. Estimation of failure probabilities. Private Communication, 2008.

[30] Harada K, Enomoto A, Uede K, Wakamatsu T. An experimental study on glass cracking and fallout by radiant heat exposure. In: Proceedings of the sixth International Symposium on Fire Safety Science, IAFSS, 1999, p. 1063-74. 
[31] Mowrer FW. Window breakage induced by exterior fires. Report NIST-GCR-98-751, Gaithersburg, MD, U.S.A.: National Institute of Standards and Technology; 1998.

[32] Xie Q, Zhang H, Si D. Experimental study on critical breakage stress of float glass with different thicknesses under conditions with temperatures of 25 and $200^{\circ} \mathrm{C}$. Fire Mater $2011 ; 35(5): 275-83$.

[33] Lehman RL, Strange DJ, Fischer WF. Ceramics and Glass. In: Kreith F, editor. Mechanical Engineering Handbook. Boca Raton: CRC Press LLC; p. 12_85-102, 1999.

[34] Rosario RAF. Modelling of the behaviour of glazing systems exposed to fires, PhD Thesis, Kingston University, London, 2009.

[35] Lamers E, Derkink M. Towards design rules for structures with glass panels during impact. In Bos F, Louter C, Veer F, editors. Challenging glass: Conference on architectural and structural applications of glass. Amsterdam: IOS Press BV; 2008, p.369-76. 


\section{FIGURE CAPTIONS}

Fig. 1. Typical window glass system [12].

Fig. 2. Spectral absorption coefficient of window glass [26].

Fig. 3. Glass edge conditions studied.

Fig. 4. Predicted temperature $(\mathrm{K})$ distribution in the glass pane for an incident heat flux of $6.7 \mathrm{~kW} / \mathrm{m}^{2}$.

Fig. 5a-b-c Deformation of the glass pane for three time sequences as a result of exposure to radiant heat, boundary condition (a) unconstrained shaded edges. 5a. initial time of heating, 5b. intermediate time of $70 \mathrm{~s}, 5 \mathrm{c}$. Final time of $140 \mathrm{~s}$.

Fig. 6a. Normal stresses $\sigma_{\mathrm{y}}\left(\mathrm{N} / \mathrm{m}^{2}\right)$ distribution for an incident heat flux of $6.7 \mathrm{~kW} / \mathrm{m}^{2}-$ Boundary condition (a) unconstrained shaded edges.

Fig. 6b. Normal stresses $\sigma_{\mathrm{y}}\left(\mathrm{N} / \mathrm{m}^{2}\right)$ distribution for an incident heat flux of $6.7 \mathrm{~kW} / \mathrm{m}^{2}-$ Boundary condition (b) glass pane constrained in the four corners.

Fig. 6c. Normal stresses $\sigma_{\mathrm{y}}\left(\mathrm{N} / \mathrm{m}^{2}\right)$ distribution for an incident heat flux of $6.7 \mathrm{~kW} / \mathrm{m}^{2}-$ Boundary condition (c) glass pane fully constrained at the bottom shaded edge.

Fig. 7a. Normal strains $\varepsilon_{\mathrm{y}}$ distribution for an incident heat flux of $6.7 \mathrm{~kW} / \mathrm{m}^{2}-$ Boundary condition (a) unconstrained shaded edges.

Fig. 7b. Normal strains $\varepsilon_{\mathrm{y}}$ distribution for an incident heat flux of $6.7 \mathrm{~kW} / \mathrm{m}^{2}-$ Boundary condition (b) glass pane constrained in the four corners. 
Fig. 7c. Normal strains $\varepsilon_{\mathrm{y}}$ distribution for an incident heat flux of $6.7 \mathrm{~kW} / \mathrm{m}^{2}-$ Boundary condition (c) glass pane fully constrained at the bottom shaded edge.

Fig. 8a. Equivalent stress in the glass pane $\left(\mathrm{N} / \mathrm{m}^{2}\right)$.for an incident heat flux of $6.7 \mathrm{~kW} / \mathrm{m}^{2}-$ Boundary condition (a) unconstrained shaded edges.

Fig. 8b. Equivalent stress in the glass pane $\left(\mathrm{N} / \mathrm{m}^{2}\right)$. for an incident heat flux of $6.7 \mathrm{~kW} / \mathrm{m}^{2}-$ Boundary condition (b) glass pane constrained in the four corners.

Fig. 8c. Equivalent stress in the glass pane $\left(\mathrm{N} / \mathrm{m}^{2}\right)$. for an incident heat flux of $6.7 \mathrm{~kW} / \mathrm{m}^{2}-$ Boundary condition (c) glass pane fully constrained on the bottom shaded edge.

Fig. 9. Overall probability of failure of the glass pane for different edge conditions of ordinary glass pane exposed to radiant of $9.1 \mathrm{~kW} / \mathrm{m}^{2}$. 


\section{TABLES}

\begin{tabular}{|c|c|c|c|}
\hline$\mu_{\mathrm{m}}$ & $\xi_{\mathrm{m}}$ & $\eta_{\mathrm{m}}$ & $\mathrm{w}_{\mathrm{m}}$ \\
\hline 0.1838670 & 0.1838670 & 0.9656013 & 0.1609517 \\
\hline 0.6950514 & 0.1838670 & 0.6950514 & 0.3626469 \\
\hline 0.9656013 & 0.1838670 & 0.1838670 & 0.1609517 \\
\hline 0.1838670 & 0.6950514 & 0.6950514 & 0.3626469 \\
\hline 0.6950514 & 0.6950514 & 0.1838670 & 0.3626469 \\
\hline 0.1838670 & 0.9656013 & 0.1838670 & 0.1609517 \\
\hline
\end{tabular}

Table 1. $\mathrm{S}_{6}$ SDOM direction cosines for 3D geometry [25]. 


\begin{tabular}{|c|c|c|}
\hline & Weibull Modulus, m & $\begin{array}{l}\text { Unit of area strength, } \\
\qquad \bar{\sigma}_{\mathrm{u}}\left(\mathrm{N} / \mathrm{m}^{2} / \mathrm{m}^{2}\right)\end{array}$ \\
\hline As-cut edge & 5.9 & $1.5756^{*} 10^{7}$ \\
\hline Ground edge & 9.9 & $1.8482 * 10^{7}$ \\
\hline Polished edge & 8.3 & $1.4501 * 10^{7}$ \\
\hline
\end{tabular}

Table 2. Weibull Modulus and Unit of area strength for different edge conditions for ordinary glass, used in the probability of failure model [29]. 


\begin{tabular}{|l|c|c|c|c|}
\cline { 2 - 5 } \multicolumn{1}{c|}{} & $\begin{array}{c}\text { Time of first crack } \\
\text { occurrence - Experiment }\end{array}$ & $50 \%$ OFP & $75 \%$ OFP & $100 \%$ OFP \\
\hline (a) As-cut edge & $90 \mathrm{~s}$ & $98 \mathrm{~s}$ & $115 \mathrm{~s}$ & $160 \mathrm{~s}$ \\
\hline (b) Ground edge & - & $82 \mathrm{~s}$ & $91 \mathrm{~s}$ & $112 \mathrm{~s}$ \\
\hline (c) Polished edge & - & & & $98 \mathrm{~s}$ \\
\hline
\end{tabular}

Table 3. Overall Failure Probability (OFP) of ordinary glass for different edge conditions. 


\section{FIGURES}

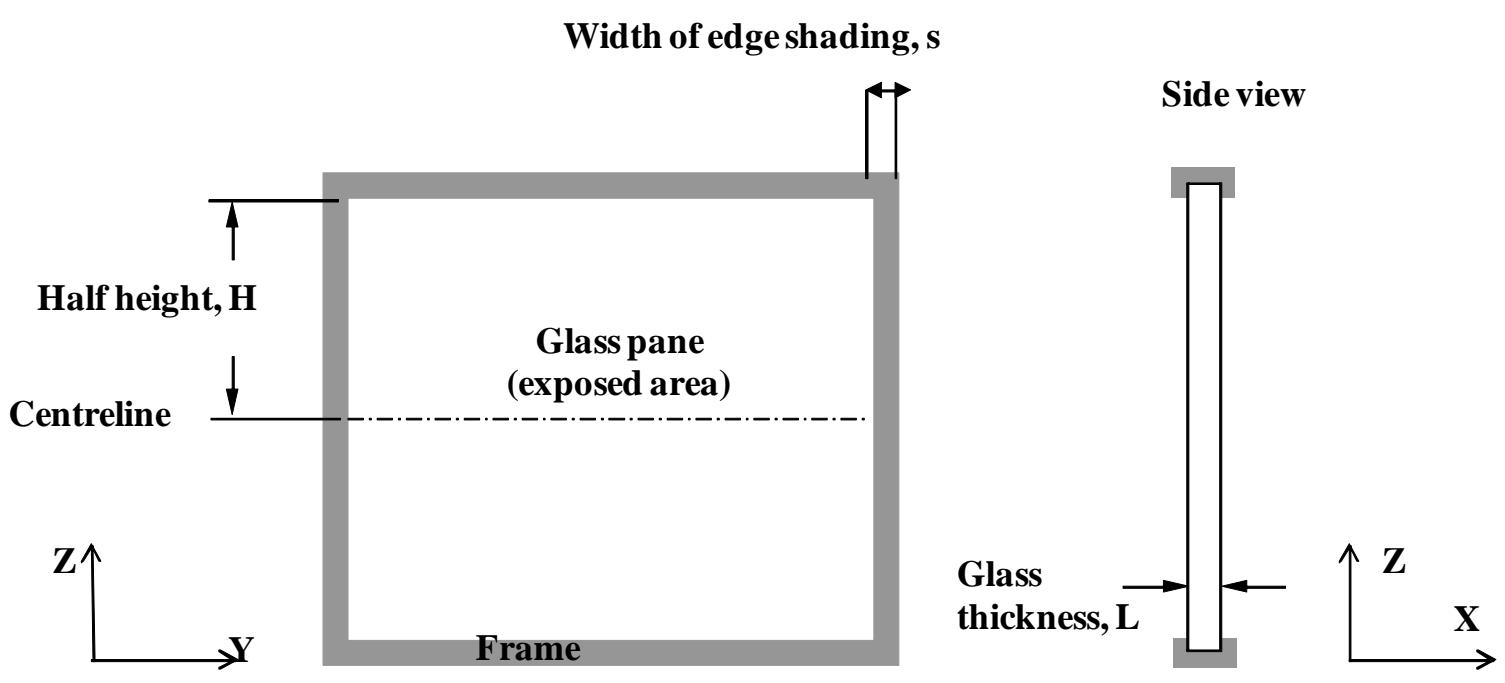

Fig. 1. 


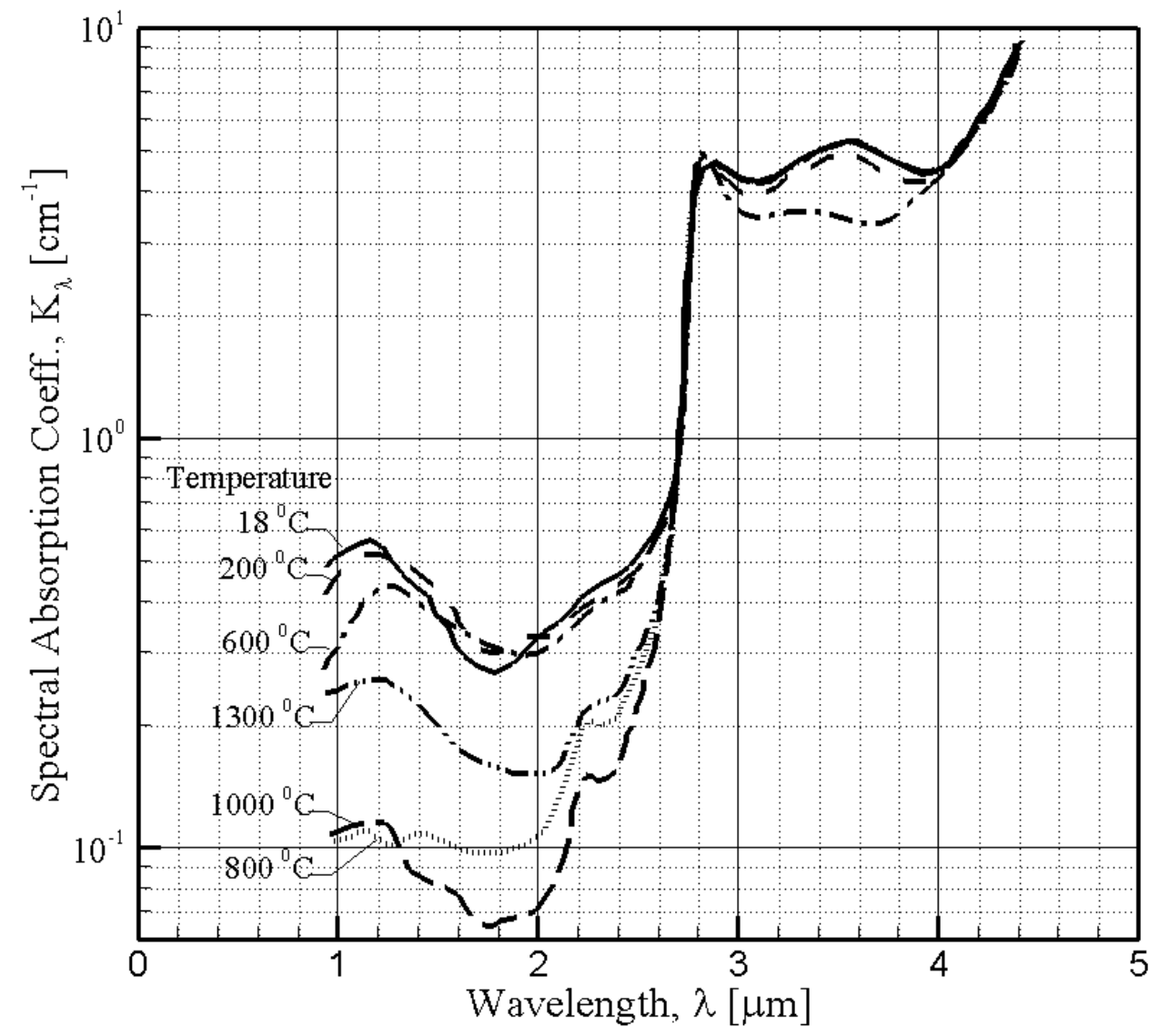

Fig. 2. 


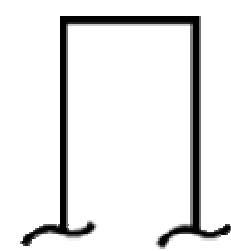

a) As-cut edge

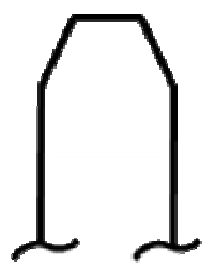

b) Ground edge

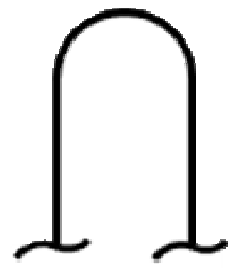

c) Polished (and ground) edge

Fig. 3. 


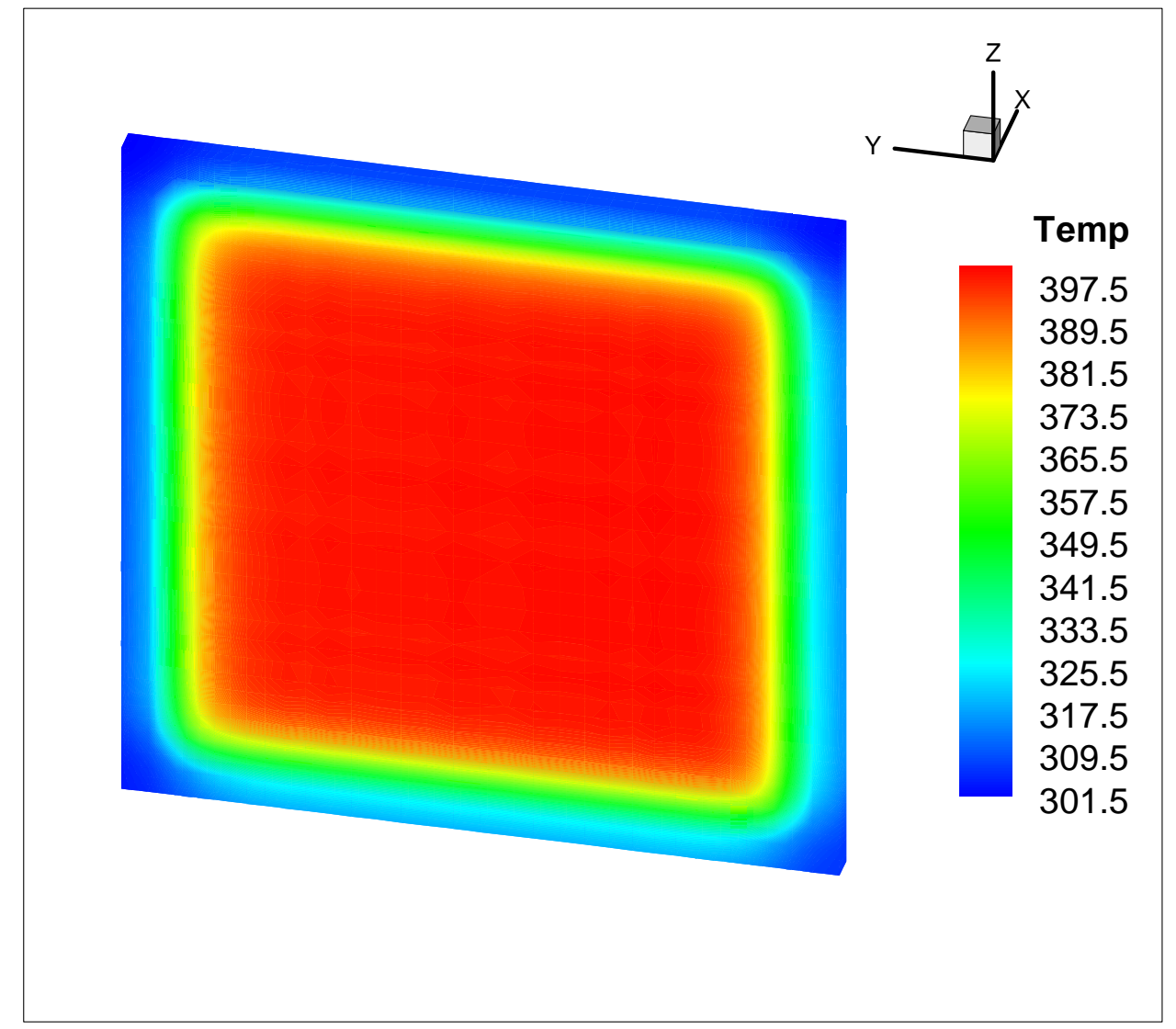

Fig. 4. 


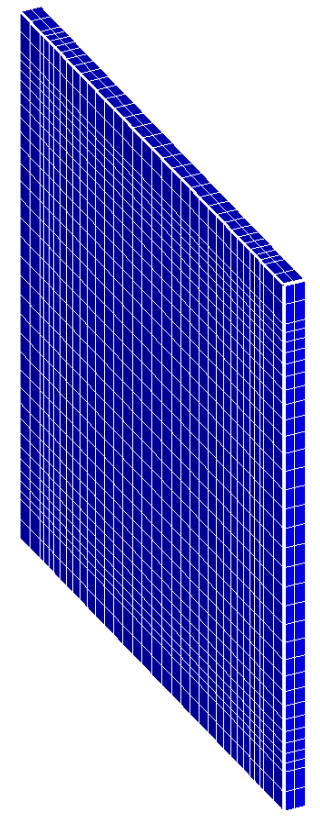

(a)

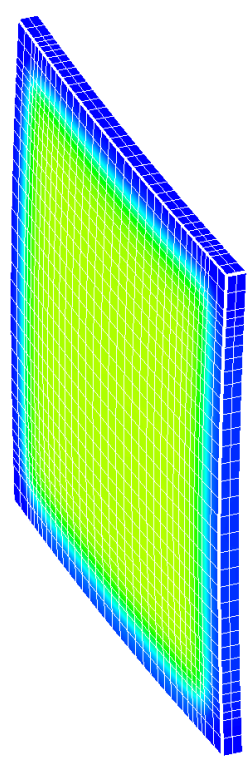

(b)

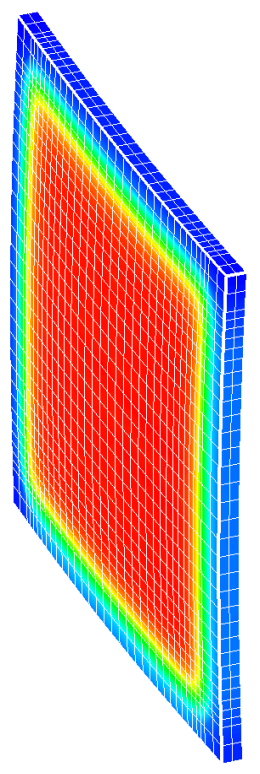

(c)

Fig. 5 a-b-c. 


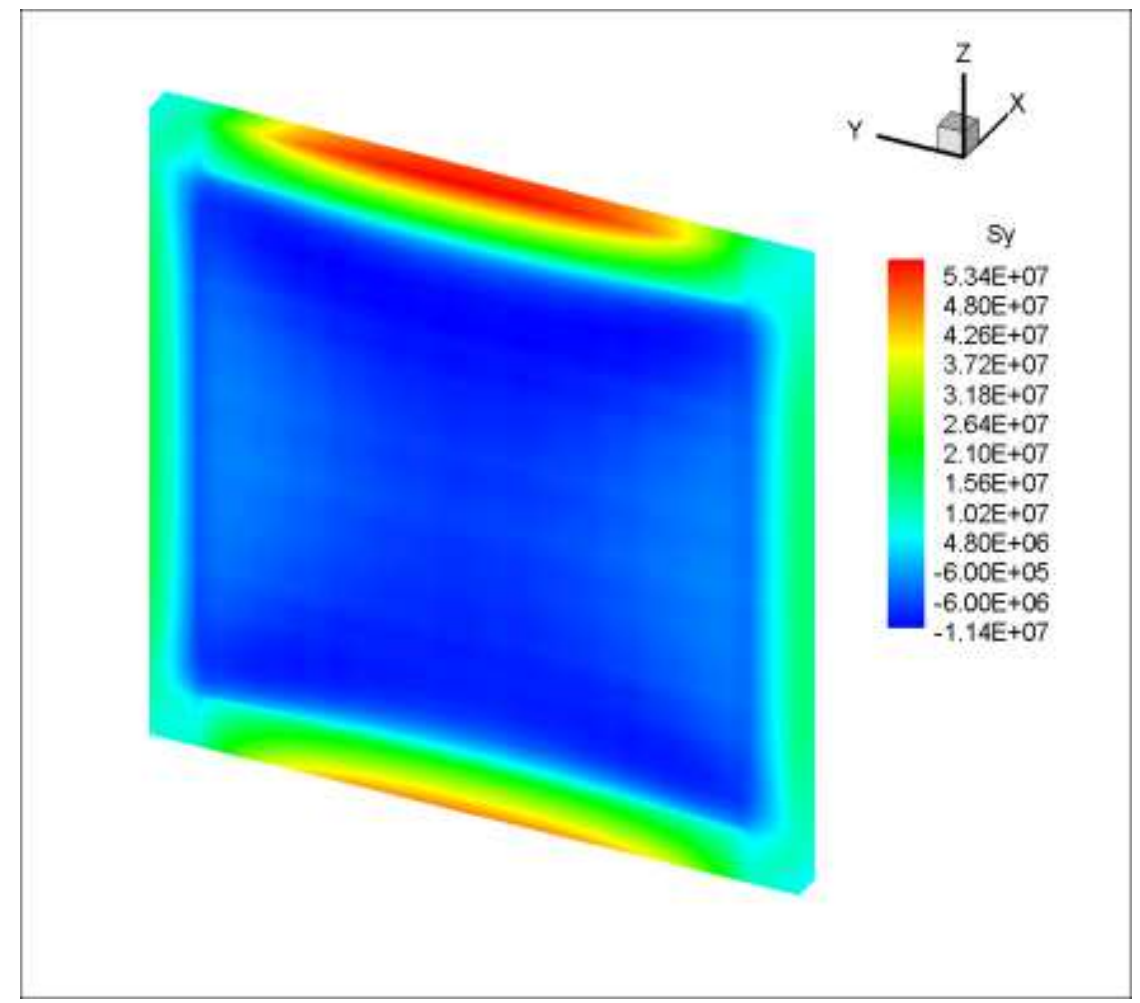

Fig. 6a. 


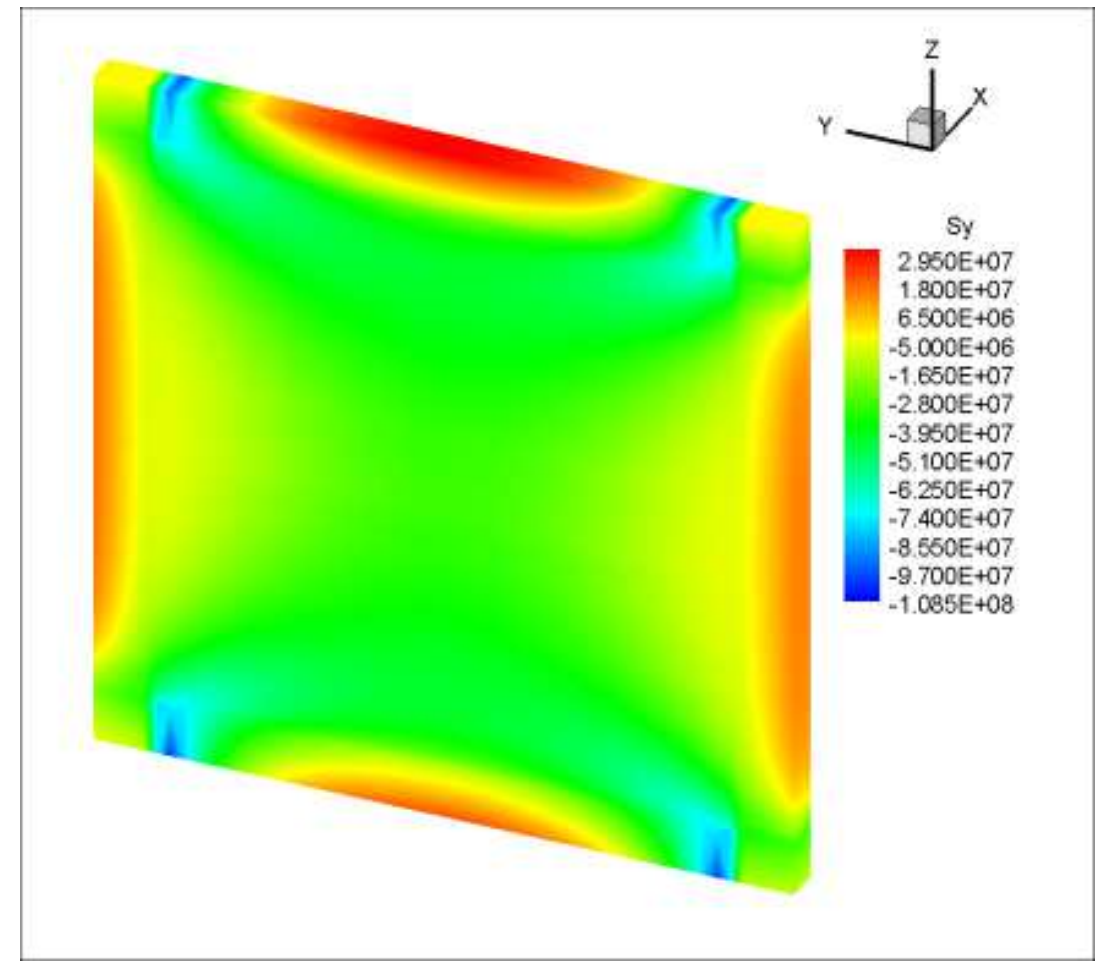

Fig. $6 b$. 


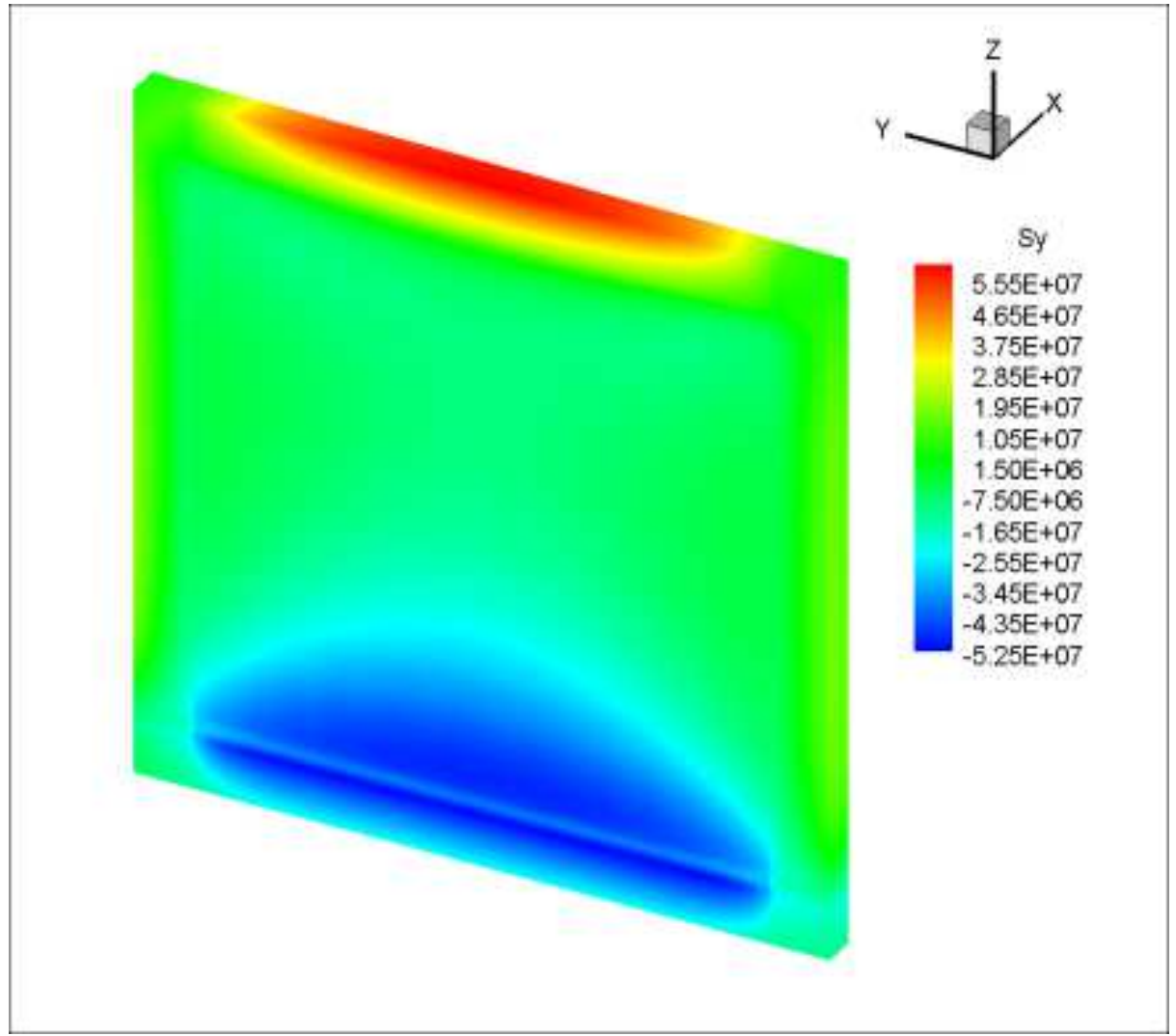

Fig. 6c. 


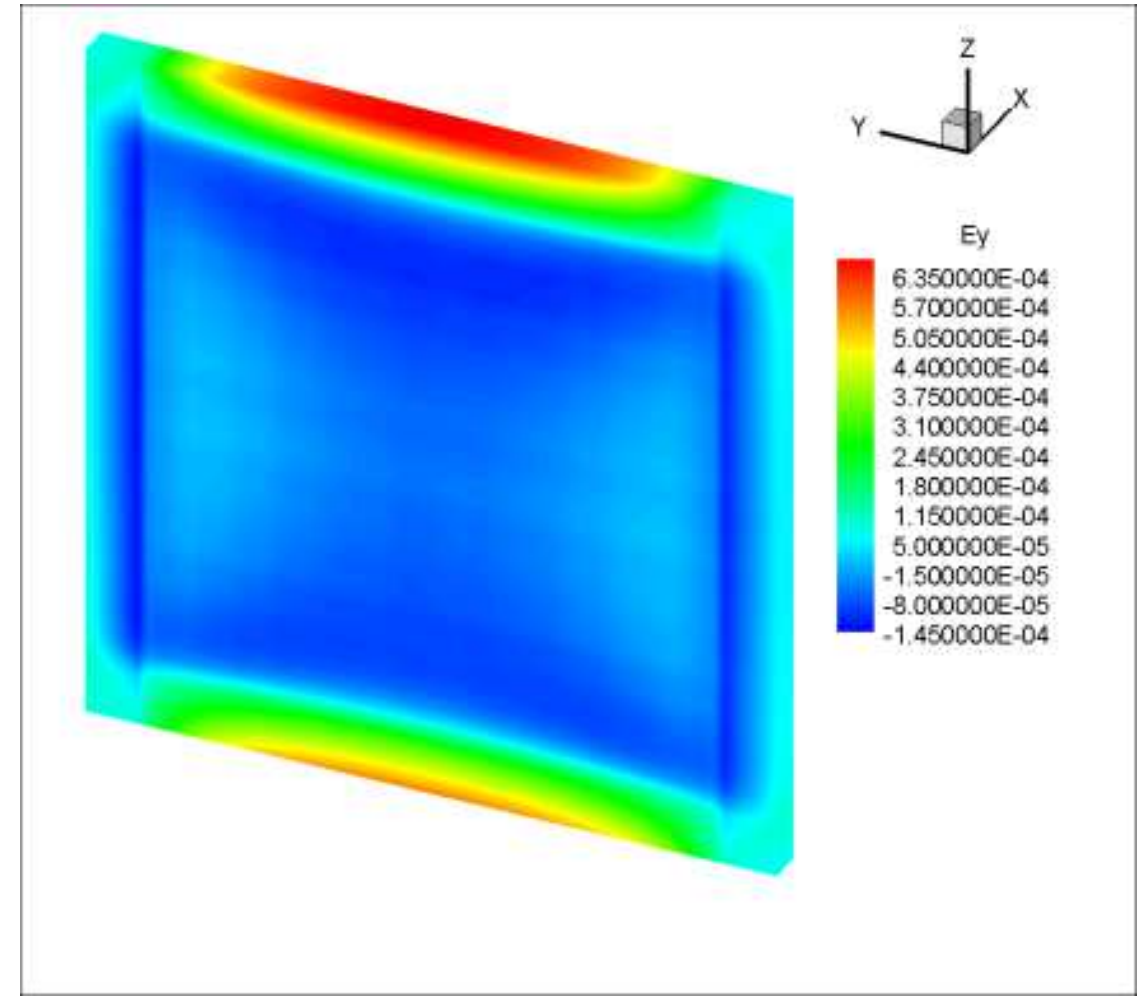

Fig. 7a. 


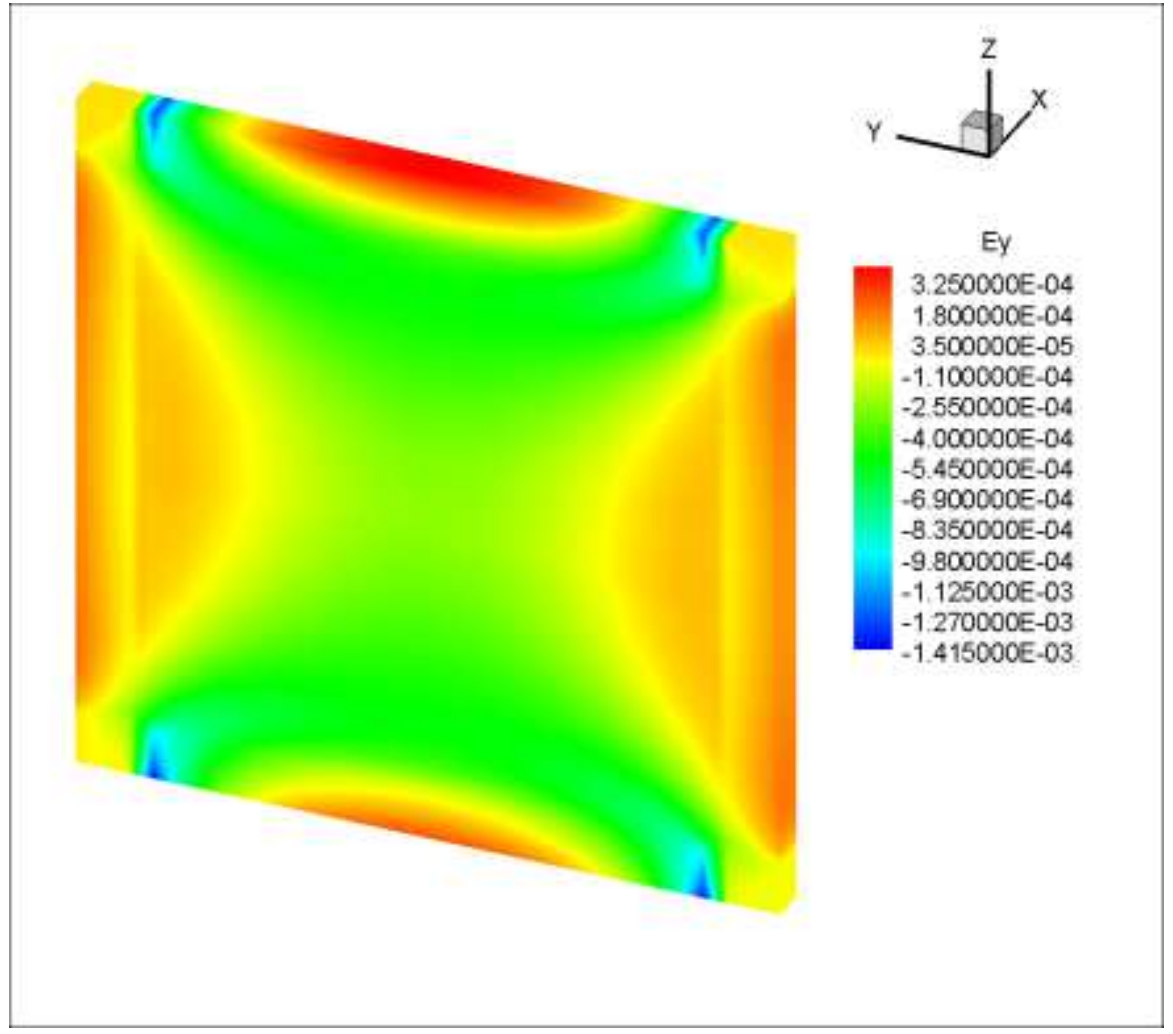

Fig. $7 b$. 


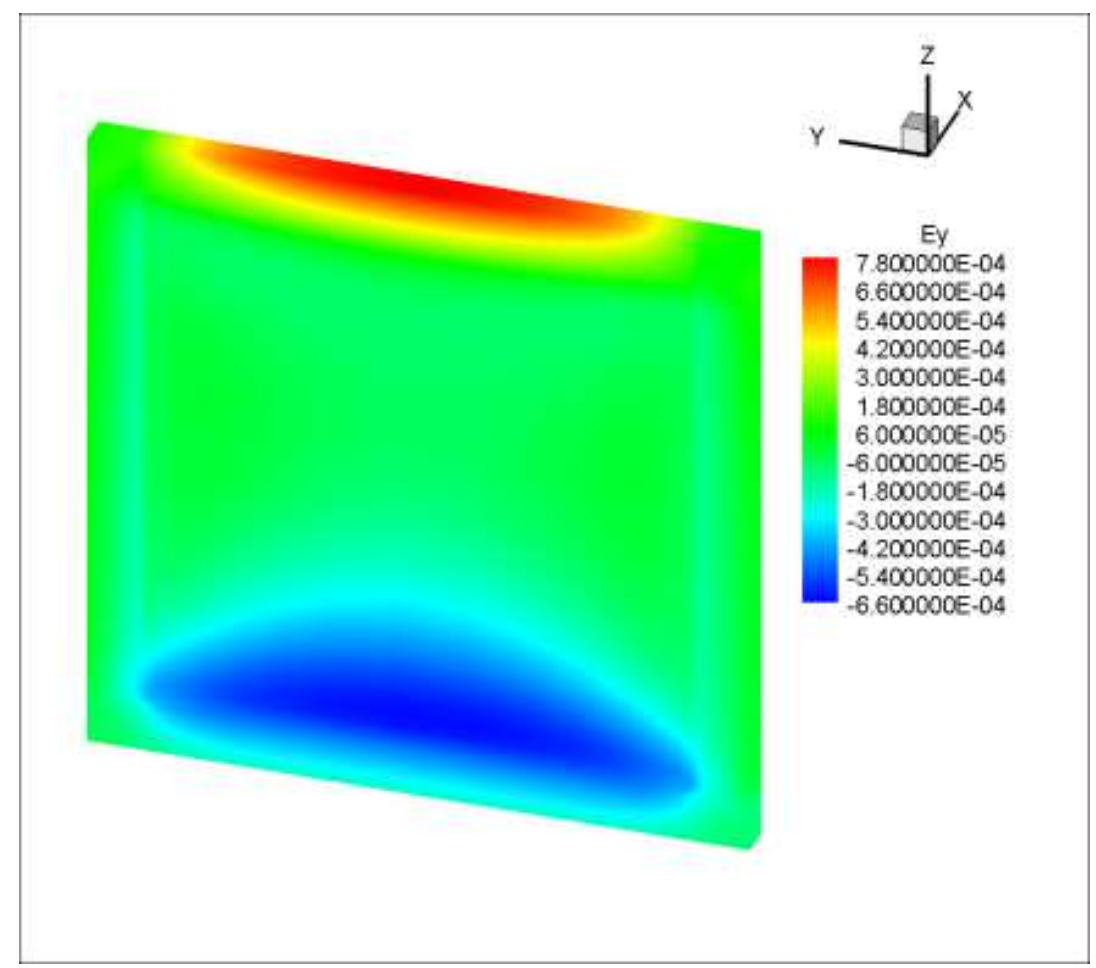

Fig. 7c. 


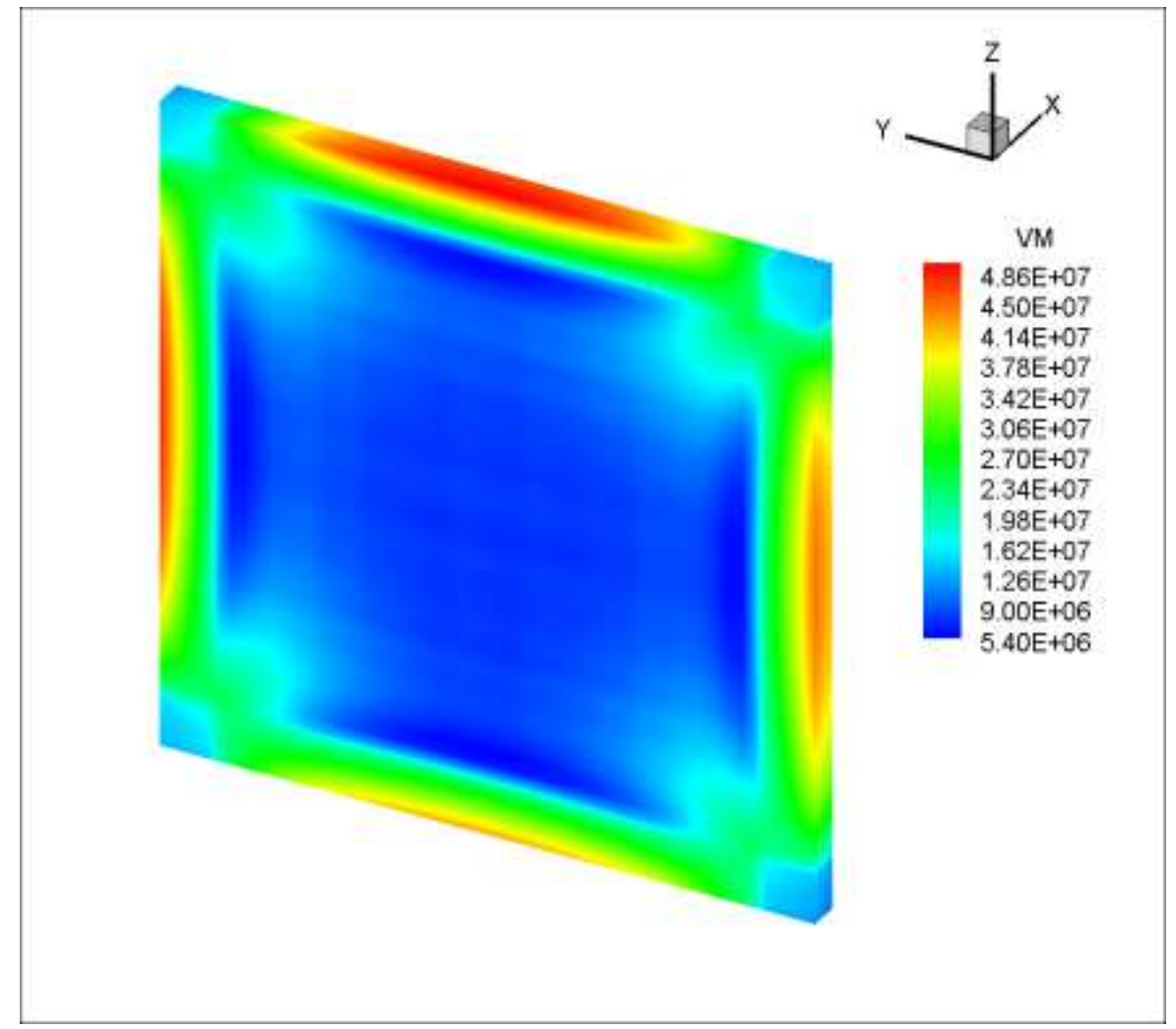

Fig. 8a. 


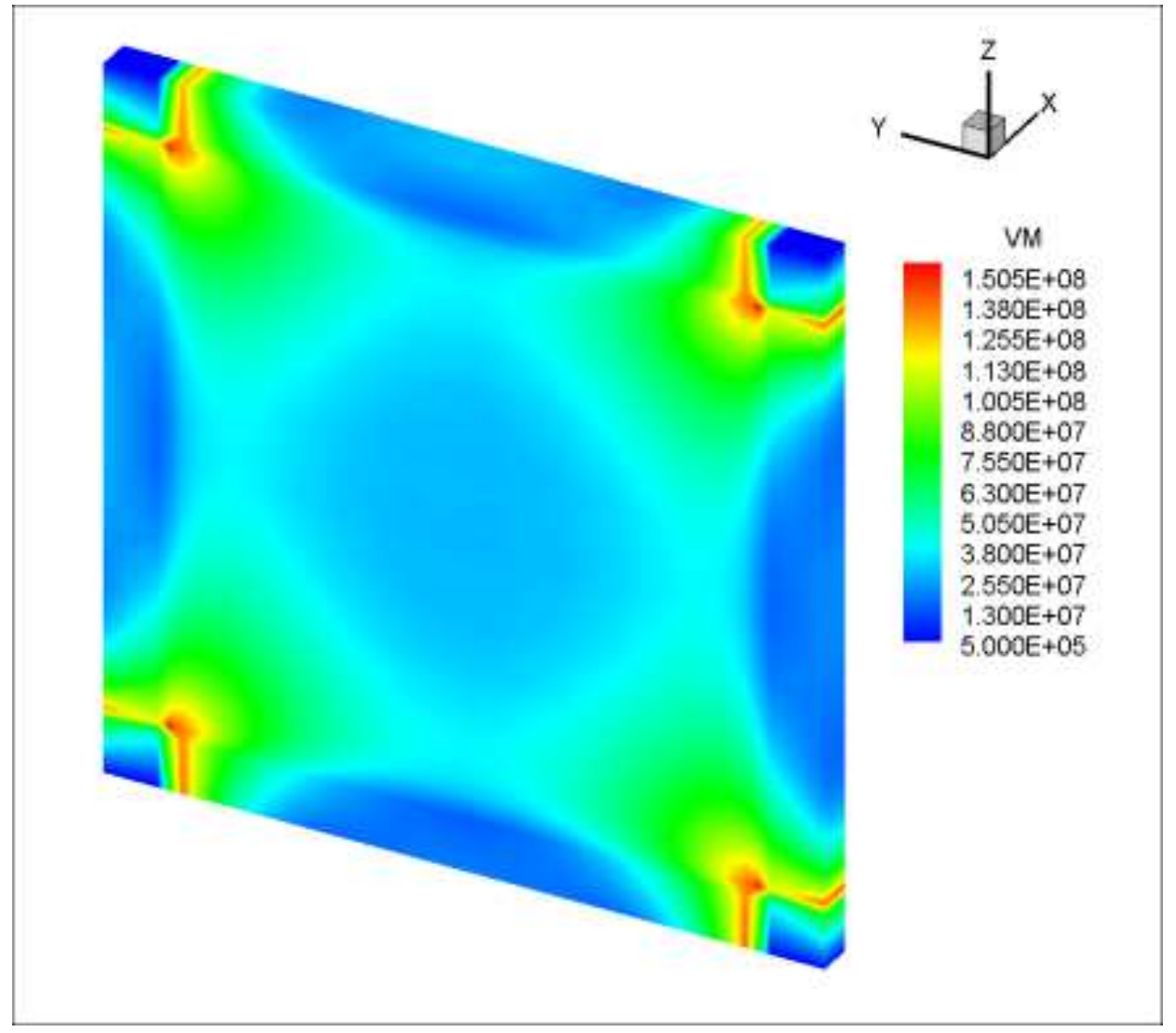

Fig. $8 b$. 


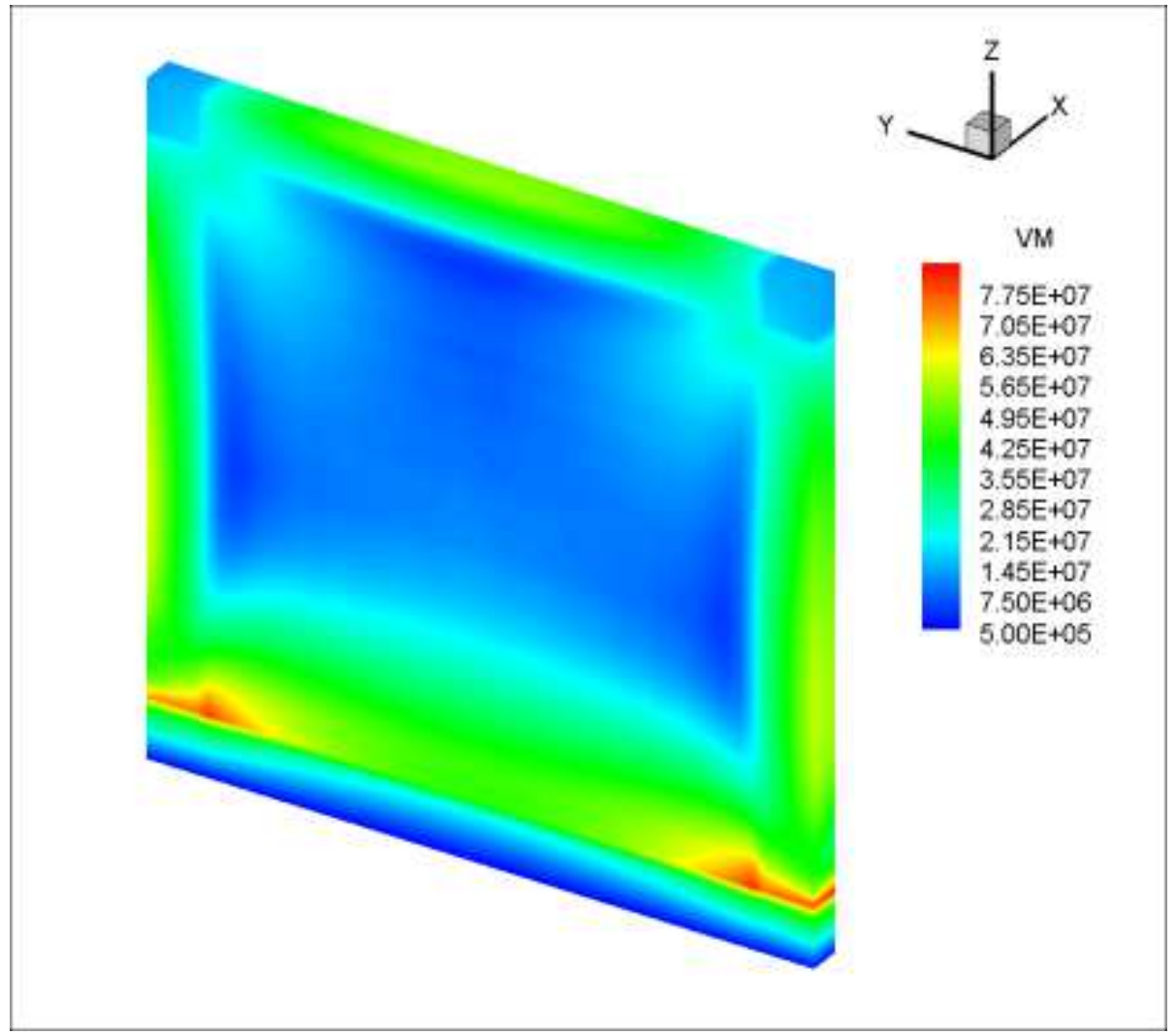

Fig. 8c. 


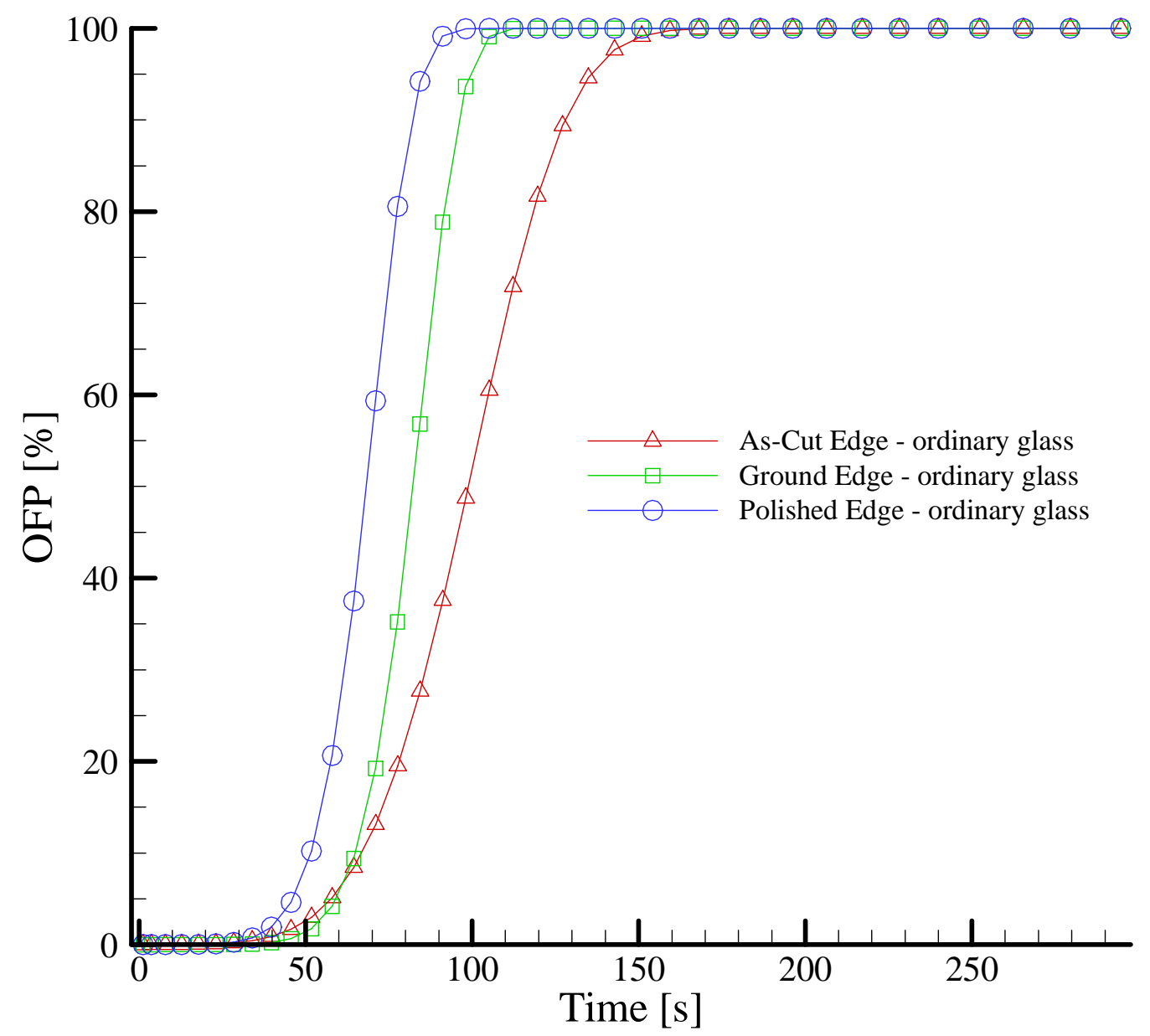

Fig. 9. 